\title{
CHAIRMAN'S SPEECH
}

\section{TRAUMATIC DISEASES AND SPORT INJURIES.}

\author{
SHIRO MIZUMACHI \\ Department of Orthopedic Surgery Yokohama University, School of Medicine.
}

\section{Injuries Caused By Sports.}

Even if precaution is taken sport injuries can not be completely avoided. But there are injuries that can be prevented. Therefore we must investigate the cause of the injuries and the type of injuries. The late professor Saito made a report going into details. On the other hand when we look at the popularization of sports in our country, a big change has come since the last war. Before the last war students participated in sports the most but post-war everyone is enjoying it. The obtained materials of this report have been through the kindness of many persons besides our own investigation in our department. The total number of persons examined were 15,465 cases.

It is common sense that various injuries occur according to the various sports. From our data we have obtained the following results.

Baseball : sprained finger. contusion of the shoulder, elbow pain (baseball elbow), lumbago, knee contusion, sprained ankle, internal derangement, fibular fracture, etc. So called pitcher's fracture is characteristic.

Soccer: sprained ankle, contusion of the knee, forearm frature, etc.

Basketball : sprained finger, sprained ankle, Achilles tendon rupture, lumbago, etc.

Tennis : Achilles tendon rupture, sprained ankle, foot contusion and wound, lumbago, elbow pain, etc.

Volleyball : sprained finger, wrist contusion, lumbago, ankle sprain, knee contusion, etc.

Rugby: knee contusion, clavicular fracture, shoulder contusion, shoulder luxation, etc.

Field and Track: forearm fracture, lumbago, pulled muscle of the thigh, knee contusion, fibular fracture, Achilles tendon rupture, sprained ankle, foot pain, etc.

Swimming: lumbago, cervical vertebra luxation fracture, head contusion etc. Cervical and head injuries caused by diving is not to frequent but the prognose is usually very bad.

Gymnastics : humerus fracture, elbow contusion, forearm fracture, wrist sprain, lumbago, breast contusion, clavicular fracture, knee contusion, shin bone fracture, ankle sprain, etc. In grammer school children the supracondylus fracture is common.

Judo: clavicular fracture, rib fracture, breast contusion, shoulder contusion, elbow contusion, knee sprain, shin bone fracture, etc.

Sumo : clavicular fracture, rib fracture, breast contusion, lumbago, supracondylus fracture, elbow contusion, shin bone fracture, etc.

Ski : knee contusion, femur fracture, shin bone fracture, shin contusion, ankle 
sprain, etc. Mostly injuries of the leg.

Skate : head contusion, face contusion and wound, brain concussion, radius fracture, wrist sprain, thigh contusion and wound, knee contusion, shin bone fracture, shin contusion and wound, ankle sprain, etc.

Bicycle: knee contusion, clavicular fracture, etc.

Mountain Climbing : knee contusion, ankle contusion, etc.

When we summarize these results, knee and ankle contusion can be seen in all sports. In children the supracondylus fracture of the humerus is common. In sports using the ball, sprained finger is very common.

Next the cause of sport injuries has been investigated. They are unexperience, not enough warm up, fatigue and poor body condition, carelessness, to much selfconfidence, foul and rough play, poor equipment and facility, inevitable, etc. The largest cause is unexperience and not enough warm up, so these can be avoided to a large extent. In other words sport injuries can be decreased logically. Actually during a match there is not so many injuries. An other thing we must be careful of is poor equipment. Like in skiing the Kandahar binding is very superior in down hill and slolam races, but when a person falls the ski will not come off, so many injuries occur because of this.

One more thing we must be careful of is the injuries caused by physical fatigue. Toriyama of our department has been studying this for the last few years by using professor Motokawa's voltage producing electrical phosphene method. He has found that athletes injured had a marked difference in the threshold value. Nakano of our department studied this from the standpoint of industrial injuries. The results were, persons injured had, had, high threshold value in the morning.

Next a characteristic thing in sport injuries is fracture caused by the abnormal contraction of the muscle. The so called pitcher's fracture is a torsion fracture of the humerus. The fracture of the spina iliaca anterior when running and jumping is caused by the abnormal muscle contraction also. These can be avoided up to some extent with adequate warming up.

I would like to say a few things concerning the treatment. The largest problem in the treatment of sport injuries is the degree and amount of rest required. If to much absolute rest is prescribed it takes much effort to make up for the lost time and if to little rest is prescribed it takes longer toc ure the injury. We must always have this in mind when we treat an athlete. Also the most trifle matters must be considered when applying the treatment.

Traumatic Diseases Caused by Sports.

A symmetrical problem to sport injuries is sport impediments. This has a very delicate difference with the body condition adaptability of sports. Many studies have been made on the problem of sport impediments, but the most famous is Baetzner's study (Germany). A catcher of a certain university baseball team came with a sore elbow and we removed a small piece of bone. It was a osteochondritis dissecans which is thought to be caused by trauma. This sort of case can be seen in the knee also. From this standpoint traumatic diseases caused by sports can be seen rather often. Among these, baseball shoulder, baseball elbow and tennis elbow seems to be the most frequent.

Baseball shoulder is a big problem to a person playing the game. Bennet(America) 
classified this into two groups, the anterior group which results from lesions in the tendon and the posterior group which is caused by the deposit of bone in the joint. I have studies this problem for about 20 years with much interest. I have classified this into three groups, the tendogenic group, the arthritic group and the myogenic or fasciogenic group.

The tendogenic group is equivalent to what Bennet call the anterior group, and includes lesions of the supraspinatus tendon and biceptal tendon. We call this group tendogenic because it can be regarded as a sort of tendovaginitis. Clinical diagnosis of this group is rather easy because there is always the tenderness along the course of these tendons.

The arthritic group belongs to the posterior group of Bennet. Tenderness is found in the posterior subacromial portion. The advanced stage of this type is the so-called arthrosis deformans, and seldom responds to therapy.

The myognic or fasciogenic group has pain in the dorsal margin of the deltoid muscle. Bennet includes this type in the posterior group. I have performed operations on this group with good results.

Seeing many cases of baseball shoulders, I think it can be avoided to some extent by some precaution. Over agony must be prevented and cold weather must be considered. Another thing is, not to change one's form as much as possible.

Baseball elbow is another big problem. Most of the cases are thought to be caused by trauma. Osteochondritis dissecans given before is one of the causes.

Next is tennis elbow. There are not very many cases of typical tennis elbows reported yet. But with the grip changing I think they will increase.

I have given only a few cases of traumatic sport diseases. There are still many others but I will not report on them this time.

Conclusion.

Thinking over the facts that I have given, I think that a much better connection between sports and medicine is required. Physical education of sportsmen is needed as I have stated before. Besides technical coaching, training from the standpoint of medicine must be considered. If this is perfected I am sure sport injuries and traumatic diseases caused by sports will decrease.

\title{
THE ALLOWABLE LIMIT OF THE QUANTITY AND QUALITY OF THE EXERCISE FROM THE STANDPOINT OF PHYSICAL STRENGTH
}

\author{
ISABURO SHIRAI \\ Showa Medical College Physiology Department
}

There are many unsolved and unclear problems concerning the connection between sports and physiques. So if our recent experiments have some influence in making these problems clear I think that we have accomplished our aim.

(1) The Minimum amount of Exercise To Maintain our Physique.

There have been reports saying that if a healthy person is kept in an absolute rested condition, appetite, weight, metabolism and heart function decreases. From 
this it can be estimated that under these conditions it would be difficult to maintain health and labor ability.

But if the labor quantity index is increased to about 200-300/day, the above condition will recover but will not come back to the individual's normal condition. So in order to maintain the normal physique the minimum labor quantity index must be about $500 /$ day.

In usual mental laborers, labor quantity index is about $200 /$ day, and if the other body movement is saved as much as possible in the off work hours, labor quantity index would be about 100 and the total amount would be about 300 , so if some exercise is not done the physique will decrease gradually.

Matsumoto of our department examined the fatique of the designer which had the highest tuberculosis rate and can-makers which had the lowest tuberculosis rate at an electric factory. The designers who moved there body the least had very low flicker rates at the end of the week and at the time of finishing work had the most decrease in the phagocytose function of the white corpuscles. Compared to this canmakers who are muscle laborers had the lowest decreasing rate and the engineers were in the middle classification. From these we can estimate that body movement up to some extent is necessary to maintain both health and labor funtion.

(2) The Limitted Necessary Recreation Sports To Maintain Physique.

In order to maintain health and labor capacity, the body movability must be more than the minimum labor quantity index of 500 , but there must be a certain limit to this figure.

Nishino of our department has reported that if the normal condition established limit is passed, even if the exercise is 30 minutes the phagocyte function of the white corpuscles usually decreases, but oppositely if the strength of the exercise is under this condition it increases usually.

The normal condition established limit is important in deciding the recreation sport's limit but this differs according to the sports very much.

So we made the average strength during a certain period constant, and changed the strength of the exercise R.M.R. from 4.5 to 11.5 and investigated the various changes in the body function. Even if the exercise quantity is the same and if there is a strong exercise during it, the respiratory and circulatory system stress increases, and the recovery process has a tendency to be delayed, but if the exercise is below the strength of the maximum oxygen intake there is hardly any fatigue reaction in the blood and urine.

So the maximum oxygen intake excercise strength R.M.R. 1.25 (continuous 5 minutes) and the limit of the various body function according to the exercise which are heavy muscular laborers with no shift R.D.R. 7.0 (continuous 40 minutes) normal condition established limit R.D.R. 4.5 (continuous 180 minutes), usual industrial laborers R.M.R. 3.4 (continuous 480 minutes) were made into a double logarithm graph and if these are connected it becomes a single straight line like graph I.

From this graph most of the sports considered as recreation sports, the strength are usually about the same or below the usual condition established limit. But if these sports are continued for a very long time the result became the opposite.

Therefore the quantity and quality of the exercise inside of these limit line can be considered necessary recreation sports. 
(3) The Limit of The Athletic Sports Necessary To Increase The Physique.

If a strenuous exercise is done considerable fatigue is felt and the body sickness resistant decreases, but in order to strengthen the physique this sort of exercise is necessary.

In order to obtain a fine physique by training through sports it is a problem how much exercise is necessary.

We have measured the maximum oxygen intake $(\mathrm{m})$ and the maximum oxygen volume (d) of first class track athletes in Japan and have made a double logarithm graph as shown in graph 2 like graph I from the individual continuous time ( $t$ ) obtained from the form $\mathrm{mt}+\mathrm{d} / \mathrm{t}$.

As these 2 graphs shows, the maximum using power not only differ with the sex and age but has various figures according to the amount of training and continuous time, but I think that the track athletes maximum using power curve shown on graph 2 can be considered as just about the same as the limit of the maximum quantity and quality of the exercise of the various sports when done all out.

As shown in graph 2 the quantity and quality of the 100 meters sprint and marathon measurements taken by Knoll and Klatschkow and the quantity and quality of the exercise when done all out on boat races and rugby measurements, both reach the limit line and can be understood easily.

Naturally during the game they do not reach the limit line.

This has much difference according to the age and sex, so graph 3 and 4 show the sexual and age difference.

A little difference can't be neglected but as a whole the area between the recreation sport limit line and maximum using power curve can be considered athletic sports.

(4) The Allowable Limit of Training By Sports.

If adequate rest and nourishment is not supplied and strenuous athletic sports are continued, over work and fatigue appears.

When we average the practicing quantity and quality of first class athletics of various sports in Japan, graph 5 was obtained.

The usual condition allowable limit of first class athletics of Japan which we measured were about $20 \%$ larger than the average male adult.

But even though the oxygen intake volume may hold a constant figure for a few hours, the labor strain equal to the usual condition established limit can't continue accordingly. This is shown on graph 6 .

It seems reasonable to call off the continuous training time to 2-3 hours.

Also in the case of the usual industrial laborers, during working hours the labor stress musht be above the usual condition's established limit, but rest and light work is inserted in between so the total labor quantity doesn't change.

Certainly it can be estimated that there is about a $20 \%$ difference in the limit volume between athletes and industrial laborers because of their objective and subjective conditions.

When we compared the various sport's athlete's practicing amount to the exercising quantity and quality bordered by the $20 \%$ incisioned line of the industrial laborers actual working hour labor volume and like graph 5 , the soccer athletes and track athletes training quantity is not up to the quantitative limit but the strength 
is just about equal to this line. Therefore the daily practicing amount of these athletes are not an unreasonable figure.

The strength of boat and rugby athletes practicing is much larger than the former.

The strength of these athletes shown in the former graph are equal to the $20 \%$ increased parallel line of the normal adult male's end of the exercise limit line when the pulse is over 180 /minute.

From these facts these athletes train for 2-3 hours till agony is felt, so if sufficient rest is not taken practice can't be continued everyday.

Therefore the exercising quantity and quality inside the dotted line triangle surrounded by the quantitative and qualitative limit line given in graph 5 can be thought as the allowable limit of athletic sports training under various conditions.

The dotted line allowable limit triangle in graph $\mathbf{5}$ is that of first class athletes so naturally a normal male adult's standard allowable limit triangle should be $20 \%$ lower.

(5) The Allowable Limit Of The Quantity And Quality Of The Exercise From The Stand Point Of Sex And Age.

In the difference of sex and age the body ability variates also. The allowable limit of a female athlete is a litte larger than that of a normal male. A 15-18 year old female has about the same maximum power output as a 14 year old male.

Usually the energy demand in exercising has direct proportional ratio with the surface area which is the function of the height and weight. From the stand point of energy metabolism the stress rate of the quantity and quality of exercise rather has direct proportional ratios with the maximum power output of the unit body surface area.

So like the former (table I) when the 18 year old male is made the standard level and the proportional ratio of the maximum power output of the unit body surface is obtained like the middle row of the table, the sex, age and training difference is a little less and a reasonable figure can be seen.

Also we have obtained the next figures in order to see sex and age difference in the running ability during a certain time.

H.E. $=$ F.L.(H : Calory demand, E : Effective rate, F : Driving force, L : Running distance) $\mathrm{E}$ is about constant and $\mathrm{F}$ has direct proportional relations with the body surface area and speed, so if the time is made constant

$$
\mathrm{L}=\mathrm{K} \sqrt{\frac{\mathrm{H}}{\text { body surface area }}}
$$

If the 18 year old male is made the standard and the obtained results are like the third row of the table, this figure shows the difference caused by sex and age is smaller.

But the difference in the track athletes are due to practice.

In the end when we obtain the direct proportional rate between the normal condition established limit and the maximum oxygen demand according to the age and sex which have close relation, the relsults are like the bottom two rows of the table.

(6) The Established Limit Of The Quantity And Quality Of Sports irrom The Stand Point of The Surrounding Temperature Condition.

When the same quantity and quality of exercise is done and if there is hardly 
any difference in the energy demand, temperature condition has much influence.

In marathon if the following figures are settled the total heat producing rate $Q^{a}$ $\mathrm{cal} / \mathrm{hr}$, surrounding heat absorbing rate $\mathrm{Qe} \mathrm{cal} / \mathrm{hr}$, body weight $\mathrm{G} \mathrm{kg}$, body specific heat $0.83 \mathrm{cal} / \mathrm{kg}^{\circ} \mathrm{C}$, the hourly average body temperature increase $\theta=\frac{\mathrm{Qa}-\mathrm{Qe}}{0.83 \mathrm{G}}{ }^{\circ} \mathrm{C} / \mathrm{hr}$, so if $\mathrm{Qa}$ is actually measured and $\mathrm{Qe}$ is obtained by Matsumoto's form and $\theta$ is obtained table 2 can be made.

But temperature balance in sports is influenced very much by the clothing.

(7) The Established Limit Of The Quantity And Quality Of Sports From The Stand Point of The Food Intake.

We know that the energy taken by food becomes the basic energy is sports.

We can estimate that there is a maximum in the food intake and if the energy needed for sports excessess this the body gets fatigued. 


\title{
1. THE PULSE RATE VARIATION IN BODY MOVEMENT
}

\author{
Y. OGAWA, S. YUSA, Y. SUZUKI, K. WATANABE, \\ M. NEGITAYA.
}

Department of Applied Physiology Yokohama Municipal University

In order to get an accurate as possible pulse fluctuation from the beginning to the end of the exercise, by changing the intensity of the movement, we have used the bicycle ergo meter. Strain was $3 \mathrm{~kg}$ constantly and the revolution was changed to 50 , 100 , and 200 rounds per 30 seconds. A tachogram of the pulse fluctuation was made by using the pulse intervals of the E.C.G. as a plot.

Light labour with the strain at $3 \mathrm{~kg}$. and 50 rounds per 30 seconds, we compared the frequent and slow pulse persons, and the tachogram level declined in both at the beginning of the exercise, but in the slow pulse persons the marked fluctuation caused by respiration before the exercise, declined from the middle to the latter part of the exercise. In the frequent pulse persons there were no marked differences.

Medium labour with 100 rounds per 30 seconds, the tachogram level declined below that of the light labour cases in both frequent and slow pulse persons. In the process of declining of the pulse period in the slow pulse persons, they had similar pulse intervals as before the exercise to a certain level during the exercise, but there was no such tendency in the frequent pulse persons.

In the recovering process post-exercise, from about 1-2 minutes the pulse period prolonged and was disordered. This tendency was much stronger in the slow pulse persons.

In the case of short and heavy labour of 200 rounds per 30 seconds, the tachogram level declined suddenly from the beginning of the exercise. During the process of declining a tendency like that of the medium exercise could not be seen even in the slow pulse persons, but in the recovering process about two minutes after the exercise the pulse period suddenly showed pulse intervals similar to that of before the exercise, climbing gradually to the original level. After this a long pulse period repeated and gradually reached the level of before the exercise. In the case of the frequent pulse persons the low level of during the exercise was maintained for quite a while after the exercise and in two minutes it didn't reach the pre-exercise level.

\section{GARDIO VASGULAR TEST OF ATHLETES}

\author{
Y. OGAWA, F. NISHIOKA, S. YUSA, \\ Y. YAMADA \\ Department of Applied Physiology Yokohama Municipal University
}

For the nurpose of examining the cardio vascular function of athletes, we have 
measured the pulse fluctuation after the knee extention and contraction strain test. We have taken the pulse rates before, during and after the exercise and made a chart to find an increasing and recovering rate, adjusted according to the sex and age. The measurements of a female is scattered more than that of a male, with little difference in the age, therefore there is only a little difference in the chart. But between the young and the old there could be seen a difference. From the records of the physically perfect child in grammer and middle school, they were distributed around the middle of the chart of each age level and had a tendency not to scatter. But in the case of marathon runners, the distribution was peculiar. The increasing rate had little difference compare to the other groups, but the recovering rate was good and was not scattered very much. Because the marathon runners who have trained their cardio vascular functions, a base line can be drawn on the chart.

Also comparing the E.C.G. with that of during the rest, we made the athletes do the extention and contraction 20 times but couldn't find any difference in the points. But right after running 1500-15000 meters the p-peak was higher, S.T. were lower and rest period disappeared. R. and T. are irregular according to the individual and lead. The relation between R.R. interval and Q.T. interval is in the normal limit of Holzman's graph usually and even with persons not in the normal limit there could not be found any irregularety in the E.C.G..

\title{
3. THE INFLUENGE OF HEAT ON THE BLOOD GIRGULATION
}

\author{
MASAAKIRA MAEDA
}

Kyoto Prefecture Medical University Department of Orthopedics

Introduction: Heatstroke is a disease seen in an unhealthy hot and humidity high place. When the body temperature rises over $42.0^{\circ} \mathrm{C}$. heatstroke occurs and when it goes over $44.0^{\circ} \mathrm{C}$. it is said the person would die. All the organs had engorgement and anatomically there was a marked change in the brain. The body lacked water and the blood was thick. When heat is applied to one portion of the body, for instance like local bath, there is a change in the blood stream of the whole body. MoratDastre says, between the skin blood vessels and the abdomin and breast blood vessels, the reaction is in the opposite direction, but the kidney, heart and brain blood vessels react to the same direction. I have used a thermometer made under the direction of professor Kurusu and investigated th echanges in the blood distribution of all parts of the body.

A. We investigated the normal blood stream of a rabbit in a room $10^{\circ}-14^{\circ} \mathrm{C}$. Next we changed the influence to $45^{\circ}-50^{\circ} \mathrm{C}$., humidity $86-98 \%$ and investigated for about 2 hours till they died.

Blood pressure rises with the temperature and 30 minutes later it was $10-15 \mathrm{~mm}$ $\mathrm{Hg}$ higher. 45-60 minutes later it started to decline. Rectum temperature increasing rate up to 60 minutes was higher than of latter and they died when the temperature was about $44^{\circ} \mathrm{C}$. 
1) Head Blood Circulation: At the beginning a little anemia could be seen but past 45-60 minutes congestion was seen.

2) Lung Blood Circulation: At the beginning, for a while engorgement could be seen but after this congestion was seen for a long period.

3) Spleen Blood Circulation: At first anemia could be seen and about 45 minutes later a slight congestion was seen rapidly.

4) Liver Blood Circulation: From the beginning engorgement could be seen for a long period.

5) Intestine Blood Circulation: At the beginning anemia for a while and next engorgment for a long period.

6) Kidney Blood Circulation: At the beginning anemia for a while and next engorgement and next congestion could be seen.

7) Peripheral Blood Circulation of the Extremities : Engorgement for a while and 30 minutes later a strong anemia could by seen,

B. The normal blood stream of a rabbit was inspected with the room temperature at $10^{\circ}-14^{\circ} \mathrm{C}$. Next a hot pack $\left(46^{\circ}-50^{\circ} \mathrm{C}\right.$.) was applied to the whole extremity of one side and observed for 10 minutes, after relieving the pack off, it was observed again for 8 minutes.

The blood pressure started to increase about 3-4 minutes after the hot pack was applied and increased $10-20 \mathrm{mmHg}$. After relieving the pack the blood pressure started dropping immediately and stayed $5-10 \mathrm{mmHg}$ higher for a while.

1) Opposite Lower Extremity Blood Circulation: During the time the hot pack was applied congestion or engorgement occurred and after relieving the pack the blood circulation became bad and showed anemia.

2) Same Side Lower Extremity Blood Circulation : First engorgement and next anemia occurred. After relieving the pack engorgement came gradually.

3) Head Blood Stream : At first a little anemia and next congestion came. After relieving the hot pack engorgement came gradually.

4) Lung Blood Circulation : Engorgement came gradually and continued after relieving the hot pack.

5) Kidney Blood Circulation: At first a little congestion was seen and later anemia came. After the hot pack was relieved it became to normal imediately.

6) Spleen Blood Circulation : At first engorgement could be seen and later anemia could be seen. After removing the pack it became normal rapidly.

7) Liver Blood Circulation: Engorgement came gradually. After removing the pack anemia came.

8) Intestine Blood Circulation: When hot pack is applied anemia appears gradually and congestion comes after relieving the pack.

Conclusion:

1) When a rabbit is warmed to $50^{\circ} \mathrm{C}$. at first anemia is seen in the head, kidney, spleen and intestines, and engorgement is seen in the lung, liver and the extremities. After this engorgement or congestion appears in the back of the head, lung, kidney and spleen, and anemia came to the extremities. After the onset of heat stroke severe anemia comes to the extremities and engorgement or congestion comes to the other places.

2) When a $50^{\circ} \mathrm{C}$. hot pack is applied on one lower extremity the blood circulation 
of the lower extremity of the same side is the opposite of that of the head blood circulation. It is not similar to the blood circulation of the opposite lower extremity but is a little similar to that of the opposite kidney, spleen and intestine. The liver blood circulation is entirely opposite to that of the intestine and the lung blood circulation, and shows an entirely different reaction.

\title{
4. PROBLEMS ON KEEPING AND DEVELOPING PHYSICAL STRENGTH. SERIES NO. 1, HIGH BLOOD PRESSURE IN YOUTH
}

\author{
K. MATSUNO, H, SASAKI, H. MAEDA. \\ Yokohama Hospital of Japan Seamen's Relief Association
}

I. Why We Thought About The Problem Of Keeping And Developing Physical Strength.

We have thought of many problems which concerns our health and also that we must be able to resist sickness. For instance, 1) How good it would have been if our former navy personels or the public could avoid tuberculosis and pleuricy. 2) If we could avoid infection diseases. 3) How to save philopan addicts. (We had a chance to treat this patient) 4) How to recreate our body correctly.

So we will take the problem of youth and high blood pressure in this case.

II. The Problem Which Interested Us Is The Youth And High Blood Pressure.

1) In the philopan patient mentioned before, he had high blood pressure. The reason he became a addict was he had weak will power, over smoking and drinking and very nervous, ete.

2) Youth with high blood pressure recently had: (1) Many had marked high blood pressure. 2) Urine albumine negative. (3) Increase of many reflex. (4) Mental will power was very loose and weak. (5) Other hereditary and physical problems have not been thoroughly examined yet.

3) Blood pressure of former navy students. (1) During 1932-1934 and 1939-1941 the blood pressure of the navy students (17-21 years) were taken and the results were, as a whole, lower than the ones mentioned before. (2) Former navy students were controled rather well mentally.

4) Considering $2 \& 3$ mentioned before I think that (1) Mental tension, (2) Physical strain, (3) Hope for the future, had some meaning.

III. Conclusion.

1) we do not no if high blood pressure in the youth is a morbid symptom of a preparation stadium.

2) So we can't give the cause but we have been taught that the youth about 20 years in age are trying to get liberty beyond our commen sense.

3) Because of these reasons I think we must try hard to persuade these people in the right way. 


\title{
5. ON THE MINUTE FLUGTUATION OF THE GARDIAC GYGLE FROM THE VIEW-POINT OF PHYSIGAL FITNESS (REPORT 1)
}

\author{
Y. OKA, N. UTSUYEMA, T. SEKINE, \\ K. NODA. \\ The First Department of Physiology School of \\ Medicine, Tokushima University
}

\begin{abstract}
Cardiac cylce continues even in rest time according to the respiratory movement. It becomes short when inhaling and becomes longer when outhaling. This is caused mainly by the "Heart pause" which is the variation between T and P of the E.C.G. Fluctuation of the first order caused by respiration and fluctuation of the second order caused by 20-40 second-cycle can be observed. A sportsman's amplitude of respiratory fluctuation is greater than that of a non-sportsman's. Deep breathing causes the amplitude of respiratory fluctuation to increase very much and the degree is much greater in a sportsman.

If deep breathing is continued the cardiac cycle average gradually decreases. Also if breathing is stopped the amplitude of the fluctuation of the first order gets smaller but never disappears, but the amplitude becomes more irregular. The fluctuation of the second order still remains but the cycle decreases to about a half and the amplitude increases a little, but becomes more irregular than the time of rest. With the stopping of the breath, the cardiac cycle level gradually decreases, doesn't change or increases and these three types can be seen in both sportsman and nonsportsman. After stopping the breath and respiration is resumed the cardiac cycle level always increases once and the ampulation of the fluctuation of the first order increases remarkably also.
\end{abstract}

\section{ON THE BEHAVIOR OF THE RESPIRATORY AND PULSE RATE AND GALVANIC SKIN REAC- TION DURING SOME PSYGHIC WORKS}

\section{Concentration labour in a short period.}

KUNIE HASHIMOTO.

Health Supervision Office, Welfare Department, Japanese National Railways.

We arranged 5 light bulbs on a $12 \mathrm{~cm}$ diameter disc and lighted one, two and three lights non-systematically. When two bulbs were lighted at the same time the people were made to signal. We lighted the bulbs at a rate of $90,120,150$ times a minute for 10 minutes in each case. We think everything will be concentrated on the light bulbs on the disc so it is very convinient to examine the body reaction caused by concentration.

We examined 1000 persons (22-24 year old males) with each trying three speeds, $(90,120,150 / \mathrm{min}$., for 10 minutes) with 3 minutes interval rests and inspected the 
changes in respiratory rate, pulse rate and galvanic skin reaction (G.S.R.). Respiratory rate was taken by pneumogram (Air transmission method), pulse rate by cardiotachogram and G.S.R. by Veraguth's reflex measurement method. Persons examined were let to take the best posture they liked and was in June when the climate was good.

1. Every person had 3 types of labour and were adjusted to three types of lighting speed and made into a graph. Respiratory and pulse rates increased according to the speed. We made a average rate of labour concerning the speed $90,120,150$ times/ min. Respiratory rates were $21.4 / \mathrm{min} .(+29 \%), 22.8 / \mathrm{min} .(+54 \%), 24.0 / \mathrm{min} .(+54 \%)$, and pulse rates increase were $3.7 / \mathrm{min}$. (5.1\%), 4.6/min. $(6.4 \%), 5.6 / \mathrm{min}$. (7.8\%).

2. The connection between the reflex appearence rate, average amplitude to the lighting speed is not clear in the G.S.R.

3. Mistakes in answering increased very much in the $150 / \mathrm{min}$. labour, and there seemed to be no connection between the rate of mistake and body reaction.

4. The body reaction during the labour as can be seen on the graph, a marked reaction appears at the beginning of the labour and increases with the speed of the labour. After the first increasement appears, about a few minutes later the respiratory and pulse rates reached the first maximum peak, but the pulse maximum point increases with the speed of the lighting of the bulbs.

5. A marked individual difference can be seen in the body reaction in this kind of labour strain and this does not only differ in the functional mutual connection but the reaction is not the same to the labour speed according to the arrangement and time. Body reaction is rather light compared to the labourer's subjective view, and posture has much effect, so even in the individual labour the same person does not always show a clear result as given above.

\title{
7. ON THE RELATION BETWEEN THE MAXIMUM OXYGEN DEPT AND THE ABILITY OF MUSGULAR EXERGISE.
}

\author{
I. SHIRAI, Y. KAMATA \\ Department of Hygiene, Showa Medical School
}

Maximum oxygen dept is controled by many conditions. Especially in sports the maximum oxygen dept varies very much according to the kind, amount of practice, etc.

So keeping these factors in mind, in order to make clear the meaning of maximum oxygen dept which is an important characteristic factor of the athletic ability, we have taken some first class male runners and ordinary adults and had them run various distances as fast as possible and measured their maximum oxygen dept.

(1) All the persons didn't reach the maximum oxygen dept running 100 meters.

A sprinter reached the maximum oxygen dept when running 200-400 meters. A middle distant runner didn't reach the maximum oxygen dept until running 800-1500 meters. Female runners and normal males reached the maximum oxygen dept when running 200 meters. 
The distance necessary to reach the maximum oxygen dept varied according to the individuals, but from the stand point of the running time, it seems that it was reached in about 30 seconds after running.

So we think it best that after running about 30 seconds we should make them run as fast as they can and measure their maximum oxygen dept.

(2) As can be seen on the graph, the maximum oxygen dept doesn't always run parallel with the running speed. A first class runner's running speed has a straight line relation with the size of the maximum oxygen dept. Those of normal male and female runners have an entirely different kind of straight line relation compared with the former mentioned. The running speed is small compared with the oxygen dept. We think that this is because a track runner has practiced for a long time and wasted very little energy in running and the running speed increases very much.

Also we think the reason the maximum oxygen dept and running speed of the normal male and female runner is the same is that the effect of practice is covered by the female's body factor.

\title{
8. ON THE TRAINING EFFECTS OF BREATH-HOLDING
}

\author{
T. ISIKO, K. HIROTA.
}

\author{
Physiological Department School of Medicine, Tokyo University
}

If breath-holding is practiced over and over the time can be extended. In order to find out if this is caused by mental or physical factors, we have done this experiment.

\section{1) Repeated enforcement.}

We used male and female students who had no experience in breath-holding and adult males experienced in breath-holding. They all had a one minute interval rest in between and the students held their breath four times and female students and adult males five times. The method was after out-haling deeply and inhaling deeply the individuals held their own nose and shut their mouth.

After repeating, unexperienced male and female students' breath-holding time gradually prolonged and this tendency could be seen in the following days with the average breath-holding time prolonging.

An experienced male had little difference in the time when done over and over, and the alveoli $\mathrm{CO}_{2}, \mathrm{O}_{2}$, when the breath couldn't be held any more had very little difference also.

\section{2) Effect of Practice.}

With male students we had them practice holding their breath every other day for three months and after nine months rest had them hold their breath for three times.

The breath-holding time at the first time, the average was 69.7 seconds (57-88), but 15 times later it prolonged very much to 126.2 seconds (100.2-147.9). 9 months later when it was measured again a marked decrease could not be seen.

At the same time the alveoli $\mathrm{CO}_{2}$ density increased and the $\mathrm{O}_{2}$ density decreased as the breath-holding time prolonged. The pneumograph of the first time the breath 
was held and after practice was about the same. (about 40 seconds) So the prolong of the breath-holding time is the prolong time from the beginning of the breast breathing.

3) Considerations.

As given before the breath-holding time of the unexperienced persons prolonged with practice. For the cause the next can be given. (1) The stimulation of the respiratory center drops. (2) The will power increases. (3) The variation in the peripheral circulation and tissues. (4) Mastering of the technique.

(1) If the breath-holding is the cause of the drop of the stimulation of the respiratory center, then a unexperienced person holds the breath a few times the respiratory center stumulation should change rapidly and with the experienced person it should not change but this is contradictory. Also after a nine months rest the time does not decrease and this is another cause which is difficult to explain.

(2) Will power is weak in an unexperienced person and it becomes stronger and constant in a experienced person. If this is obtained once it seems to last for at least nine months. When the breast-breathing is started a prolong can't be seen and later it is prolonged. This explains the will power effect.

(3) The peripheral changes must be investigated further and at the present there is nothing to say. It can be estimated from the change in the blood gas and pneumography that there is a change in the peripheral circulation.

(4) Mastering of the technique can be thought about. When a person does something not done before it is natural that he does not know the technique. Especially in the inter-breast movement this can be said on the inhaling volume before breathholding.

\section{THE VARIOUS GHANGES IN THE BODY WHEN SWIMMING LONG DISTANCES}

T. SAKAI, R. KOMORI, M.SATO.

Natori Researcd Institute Physiological Department, Jikei Medical College

When we give a person with practice some athletic strain it is rather difficult to determine it's allowable limit. In order to determine the allowable limit we must find what influence the amount of strain (various physiological changes) of the person tested has on the exercise volume in the various amount of training. As can be seen on the graph when the amount of exercise and strain has a straight line relation, there is no need to think about the allowable limit and it is inside of the physical limit and the recovering power is high. But when it becomes above this it is natural that the strain volume curve which apposes the exercise amount increases in the exponential function way and the recovering power becomes poor. At some point of this condition we can settle a allowable limit. When we think of this allowable volume or allowable limit we must select it at each condition.

In physical education in order to make the amount of exercise just right we must measure the strain volume and from this select a allowable volume. This report is of university students who have become able to swim this year. We had them swim 
60 minutes under the leadership of people in the swimming team with the sea temperature about 25-26 degrees C. Before we had them swim in colder waters for 1-2 hours but only a few people could complete the swimming so we tried to find what excercise volume would be best for the course of study.

But up to now the allowable labour volume of the exercise intensity has been known from the investigation of the energy metabolism. But when long swimming is done it is very difficult to measure this. So we have been trying to find a better way of measuring this and used the next method. This is, strain test, blood pressure, patella reflex limit, flexibility and leucocyte hemogram. We do not say this is the best, but we think if these 6 factors are observed it is enough. We divided the allowable labour limit A.B.C..... and the small details must be settled later.

From the above mentioned idea, we think the intensity of the swimming this time was below the allowable labour volume limit and under these circumstances we must make the strain volume larger.

\title{
10. STUDY ON ENERGY METABOLISM IN VARIOUS SPORTS (IV) A RESTUDY ON THE STRENGTH OF EXERCISE IN MIDDLE DISTANGE MARATHON RUNNERS.
}

\author{
H. OKABE, S. OGAWA, K. AKUTSU, Y. IWASAKI. \\ Department of Physiology, Tokyo University of Education
}

Actually it is impossible to measure the energy consumption during the whole course when running $1500 \mathrm{~m}, 5000 \mathrm{~m}$ and marathons. Also right after the start or before the goal the exercising intensity is unstable and the later is about the same as sprintting. In the oxygen consumption given by Klatschkow and Knoll there is some doubt in the measuring method. So we reviewed this trying to find a more stable time. Therefore we measured the normal condition oxygen consumption after entering the second wind and got our R.M.R. from this figure. So our R.M.R. is that of a normal condition and it is rather logical in showing the exercise intensity of the races. As for persons tested we had the cooperation of the best runners of our country Tanaka, Hayashida and Komura. As a result we got a much smaller exercise intensity figure than up to now.

1500 meters $12-15 \quad 5000$ meters 10-12 marathon 5-

\section{STUDIES ON THE ENERGY COST OF VARIOUS SPORTS (V) ON THE INTENSITY OF EXERGISE OF FIELD ATHLETES}

\author{
S. OGAWA, Y.ASAI, K. AKUTSU, H. KOMINE \\ Department of Physiology, Tokyo University of Education
}

As one of the researches on sport energy metabolism we have measured 8 field events and summed up the R.M.R. and reviewed this. 
We examined 11 track team persons from the Tokyo University of Education Physical Education Department. The ages were 19-22 years and they all were first class athletes, some competing in inter-college events.

We used the Douglas's method in measuring and Hygro Gas Meter in measuring the collected gas volume. We did these slowly for accuracy.

The field events can be divided into jumping and throwing, and the type of movement and equipment differ according to the event. The warming up running vary according to the athlete and event.

From the above results, all the events are maximum exercises in a short time, so compared to other sports and labours their labour intensity shows a very high figure. Also the R.M.R. figure varies according to the athletes, but this can be realized. So it is difficult to find a certain figure and it's more logical to find a certain range.

Again a athlete might have different R.M.R.'s according to the condition.

All these results are with the athletes wearing things and the figures are about $85 \%$ of their best records. We think that the exercise intensity is actually above these figures. We also think that we can estimate what a college athlete in field events are and know roughly the standard of exercise intensity.

\title{
12. STUDIES ON THE ENERGY COST OF VARIOUS SPORTS (VI) ON THE INTENSITY OF EXERGISE OF THE GYMNASTICS
}

\author{
S. OGAWA, Y. ASAI, K. AKUTSU, T. WATANABE. \\ Department of Physiology, Tokyo University of Education
}

As one of our studies on sports, energy metabolism, we will this time measure the energy metabolism rate of gymnastics.

Investigations from the stand point of respiratory gas metabolism of gymnastics have been reported by Missiuro, Yoshida, Yamaoka, Ishii, etc., but these are chinups, longontal bar gymnastics and basic gymnastic energy metabolism, and these have been reported on as regulated gymnastic events.

The contents of the gymnastic sports change a little once every 4 years but there is very little difference. These gymnastic sports take only 20-30 seconds so it is easy to measure the energy consumption and R.M.R. So we have taken events most done in the public university gymnastic meets. We examined the $\mathrm{O}_{2}$ consumption, calory consumption and the R.M.R. of side horse, parallel bars, horizontal bars, rings and long horse. Reports will be made according to this order.

The athletes were first class athletes 21 years old and both had much experience in gymnastic meets. The experiments where made in a gymnasium using the facilities and in order to make the conditions the same as the meets we had them get used to the equipment and had the athletes repeat each event 2-3 times.

First there was quite a difference in the R.M.R. according to the events, long horse had 60-90 and horizontel bar had 35-40, but as a whole they were 20-30 higher. Long horse was a special characteristic event which takes 6 seconds right after the warming up running and except free exercise there is a simularity between the exercising time and R.M.R. Rings looks like a very severe tiresome event but the R.M.R. 
is small and we think this is because there is $4-53$ seconds rests in the 27 seconds event. Also compared to this, horizontal bar has variations dilicate movements so the figure is large. Free exercise does not use equipments and is easy to see and the other events use mostly the upper half of the body where as this has a complicated flexible body movement, so used a rather large amount of calories. (13-14 cal.)

As a whole which ever one it is, exercising time, $\mathrm{O}_{2}$ consumption, calories, and R.M.R., the individual difference is larger than the difference of the same athletes. This is a very interesting problem from the stand point of gymnastics

\title{
13. ON THE ABNORMAL METABOLISM OF LONG DISTANT RUNNING
}

\author{
M. IIJIMA, S. YOGI, I. HONDA. \\ Department of Hygiene, Showa Medical School
}

The fatigue of long and short distant runners are not always the same. We thought this had some connection to the mobilization and shortage of the power source and examined the acetone, citric acid and nitrogen excretion quantity, Vakcat-iodine acid index, Donaggio's test of Athletes in the All Japan Track Meet. The results were, the figures had a tendency to be higher in middle distant runners and lower in short and long distant runners.

By this we thought the fatigue of long distant runners where caused not only by the oxygen shortage but had much connection with the mobilization of power sources. etc. We examined the leading long distant runners at the Kanto Students Track Meet. We examined the acetone and nitrogen excretion, Vakatiodine acid index, Donaggio's test before and after the races. Only the Donaggio's test showed a higher figure after the race usually. This tendency looked like it had ratio connections with the quantity of urine, but when examined closely it didn't always have relations with the urine quantity.

We repeated these examinations last July with the same athletes at the All Japan Track Meet and the results were the same.

The acetone citric acid and nitrogen excretion and the Vakat iodine acid index showed a low figure, and these could not be seen to have any direct connections with the decrease of the urine excretion and because of perspiring a lot in the early summer seemed to be the main cause, but also when sports like these which uses a great amount of energy in a short period, organs besides the liver, especially in the muscle tissues the fat and protein were directly used and this could be considered as another factor.

\section{STUDY ON THE BASAL METABOLISM OF SPORTMEN REPORT II. ON THE RELATION BETWEEN THE TRAINING AMOUNT AND BASIC METABOLISM} YOSHIO KAMATA.

\author{
Department of Hygiene, Showa Medical School
}

Associate Kawatani reported before, that the basic metabolism of superior track 
athletes of ar university showed a low figure like the normal mental labourer, but compared to this the rugby player showed a very high figure like that of a heavy muscle labourer.

So we have done the next experiment to see what connection the level of basic metabolism has with the quantity and quality of the sports and also with the amount of food. We have taken the same kind of athletes who didn't attend summer training camp for 2 month and boat and soccer players who during the same time attended training camp. and measured their basic metabolism. We also examined carefully the amount of practice, the quantity and quality of the food taken and got the next results.

(1) During the autumn season with rather little amount of practice a track and field athlete showed a very low basic metabolism and during the summer the amount of practice decreased somewhat but the basic metabolism didn't hardly decrease. A rugby player who had a very high basic metabolism during the season and by resting practice and spending a quiet life for two month, he lost $1.6 \mathrm{~kg}$ and his basic metabolism decreased $8.2 \%$. Considering the figures of the basic metabolism of various athletes during the same time, this decrease is caused by the amount of practice, consequently the quantity and quality of the food taken during that time.

Even though it decreased the basic metabolism of these rugby players were $7.6 \%$ higher than that of the track and field players during the same time.

I think that because of the heavy training for many years the rugby players' nature of the body cell active function had changed and had become suitable to higher basic metabolism.

(2) As the graph above shows, boat and soccer players' basic metabolism during training came in proportional with the amount of practice consequently with the quantity of food taken and shows a higher figure.

Also on the graph the calory volume per day does not balance but this is because there is great difference in the amount of practice daily and because we did not consider the amount of practice of days off.

When the quantity of the food of each athlete during training camp is averaged for a week to 10 days it can be estimated that it balances with the amount of training daily. When we examine the connection between the amount of practice and the basic metabolism there is a coefficient of correlation and the figure is 0.98 which is very closely related.

The results show that the athletes' basic metabolism is not only effected by the active cell percentage and the vagotonic idiosyncracy, but it is clear that the amount of practice, consequently the amount of food taken has much influence.

\title{
15. LOWERING OF ENERGY REQUIREMENT BY TRAINING-THE GASE OF STOOPING-
}

\section{YOSHIO OMATSU.}

\author{
Department of Industrial Medicine, Kobe Medical College
}

Concerning the relation between training effects and electro-myogram, Kawakami (1) reported that there is a marked difference between electro-myogram of the 
leg muscle of a normal person and stevedore. Fukuda (2) reported that by training a normal healthy person to take a special posture the oxygen consumption declined very much. My method is using the stooping posture. The knee joint is bent at 120 degrees and the foot joint at 65 degrees. By making the person hold this posture everyday or at a few days interval the energy metabolism was tested carefully and after quitting the training the condition was examined also.

The results are as follows.

Experiment : Healthy males were picked from our department and students. In order to have a standard posture a simple box was made with a moveable ceiling to adjust the height of the person. The period of the experiment was from Oct. 1954 to Oct. 1955.

Results: Training periods were everyday consecutively, 3 days interval, one week at a time and non-schedule systems. The first or second time at the beginning, about 2 minutes after taking the posture the extensor muscles started to hurt and the pain increased with the time rapidly. In about a few minutes to about 10 minutes the experiment had to be stopped temporarily, but still a pain remained on the front of the thigh. But doing this over and over the pain will decrase and the posture can be held for about 30-60 minutes. Oxygen requirement was 500-600 cc/minute at the beginning. Training everyday, a week later it became $60 \%$, about 3 months later it went down to $30-35 \%$ of the beginning. The way the oxygen requirement drops is, it goes down to a certain level and a few days it stays there and starts dropping again. If the training is stopped for some time the oxygen requirement goes up about $10 \%$ of the time of quitting, but if training is started again it drops down to the same level as the time the training was stopped easily and more training will lower the mark again. After the training is stopped for 3 days oxygen requirement doesn't go up and in about 10 days it starts to go up gradually. But 10 month after the training is stopped the amount is stll $20 \%$ lower than the very beginning. So if training is continued for some time the effect for this certain stress will last for quite a while. From this point of view I had a cart-man who is used to carrying heavy loads take the same stooping posture. Under the same condition as a normal person he showed no pain and the oxygen requirement was the same as that with 3 months training. Training every 3 days over a month the oxygen consumption dropped down to $40 \%$. With training every week it dropped only about $15 \%$ and was very difficult to go lower. Training with pauses over 10 days showed very little effect of the training. In the case of training everyday by putting a $2 \mathrm{~cm}$ board under the foot a $25-50 \%$ oxygen requirement increase was seen. In other word a little change in posture makes a lot of difference. And it is very painful in this case. Therefore in this experiment great care must be taken to have a constant stooping posture or the data will be useless.

By this experiment training effect can be seen by the time increase and the oxygen requirement decrease. Also after the training is quitted the effect lasts for a long period of time. The marked decrease of oxygen consumption can't be explained only by the quantity of the muscle but the quality of the muscle must be considered. From this point of view Kawakami's electro-myogram of the training effect is important.

Reference: (1) M. Kawakami. Jap.J.Physiol., Vol. 5, No. 1., Jap. 1955

(2) S. Fukuda. Unpublished 


\title{
16. ON THE INFLUENGE OF THE EXERGISE UPON THE EXGITABILITY OF LOGAL SWEAT GLANDS IN HUMAN SUBJECTS.
}

\author{
FUMIO WADA. \\ The First Internal Medical Clinic, Medical Faculty, Osaka Gity Universtiy.
}

We have experimented how the individuals local sweat glands are stimulated by movement.

We have measured the local sweat gland stimulation by the iodine-starch method of Wada and Takagaki. This is done by injecting various concentrations of adrenaline cutaneously on the dorsal surface of the forearm and the threshold of sweating can be obtained by the minimal effective concentration of adrenaline. We began our experiments when no sign of spontaneous sweating could be seen. We experimented on 18 males and 23 females with the ages between 16-45.

(1) As reported before the minimal effective concentration of adrenaline is balanced and has little influence by the season, so we observated the difference in day and night. The temperature variated but 14 males and females had no change and one had change so it can be thought that there was hardly any change in the day and night.

(2) By contraction and extention of the arm we had the persons make a $4 \mathrm{~kg}$ weight move 1 meter using a pulley for 40-50 times per minute for five minutes. They all had no difference in the contrast left arm.

(3) The effects of running are as given on the table. Running 100 meters there could not be seen any marked changes in the stimulation of the sweat glands like exercise of one arm. But running 500 meters there could be seen a one to two figure decrease in the threshold value, in other words an increase in the stimulation. If the amount of exercise increased this increased also. But in people who are used to exercise the recovery of the sweat glands stimulation seems to be faster.

\section{MEDICAL GLIMATOLOGY OF MOUNTAIN CLIMBING}

\section{T. WATANAABE, E. TADAKI, M. WATANABE. \\ Ochanomizu University}

Mountain climbing as a recreation or sport not only has muscle exercise and mental liberty effects, but the surrounding climate changes also has effect on the living body. Recently the number of people climbing mountains has increased and also there are many accidents too. The main reason people die is because of the violence of the weather. We have studied the atmospheric phenomena and 2-3 body changes when climbing mountains.

We took Mt. Hakuba which is rather popular for our test. The first day we went as far as Shirauma-jiri 1572 meters high and camped there. On the second day we 
reached the top 2933 meters and from here we went to Oike 2400 meters around $18: 30$ and stayed over night. People tested were girl university students. A carrying $16 \mathrm{~kg}$ and $\mathrm{B}$ carrying $14 \mathrm{~kg}$. On the way down it was a little lighter but this did not have to much difference.

The difference in temperature between Tokyo and Matsumoto was about 2 degrees C., Matsumoto being the lower (one year average) and having mountain climate. When we reached Matsumoto at $0: 800$ on the 27 th the temperature was $32^{\circ} \mathrm{C}$. From Matsumoto we got a train and it was $26.5 \mathrm{C}$ at the end of the line at $11: 39$, with the temperature difference of $6^{\circ} \mathrm{C}$ in 2 hours. From here we got a bus and next started climbing and reached 1570 meters at 12:00. At this point the temperature was $17.5^{\circ} \mathrm{C}$. a decrease of $9^{\circ} \mathrm{C}$. An hour and 50 minutes later the temperature dropped $13^{\circ} \mathrm{C}$. at this point. On the second day (28th) we got up at 0.500 and left camp at 0.620 . At $5: 15$ the temperature was $13.5^{\circ} \mathrm{C}$. As the graph shows the temperature went up with the sun to $0: 900$. From $0: 900$ to when we reached the top $13: 35$ " $\mathrm{b}$ " point in 4 hours and 30 minutes the temperature dropped

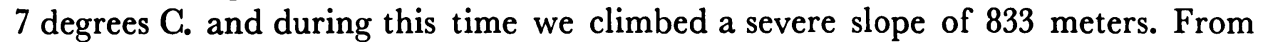
this point we started climbing down and as "c" shows the temperature decreased, but the sun became low so a marked difference couldn't be seen.

On the day we climbed, the daily temperature difference in Tokyo was about $7^{\circ} \mathrm{C}$. The climbers experienced over $10^{\circ} \mathrm{C}$. difference in about 2 hours and also the daily temperature difference was about $17^{\circ} \mathrm{C}$. in a few hours. When we compare this with the temperature of one year it is equivilant to the difference of April to August or August to the middle of October and the climbers experienced this in nearly a day or two.

On the other handt he radiant heat was very strong during the day. $\left(29^{\circ}-41^{\circ} \mathrm{C}\right.$. $)$ Radiant heat was always higher than Tokyo and the humidity was always lower. In these two atmospheric phenomena, a mountain climber is using heavy muscular exercise and perspiring a great deal. The streams varied at places with the temperature between $12^{\circ}-3^{\circ} \mathrm{C}$. and this gave the climbers spirit.

Climbing does not require the moment starting power like other sports, but the pulse rate was 1.5-2.0 times of that of during rest time. When climbing a severe slope it was over about 3 times. This kind of pulse beating can't be found in other sports very often. Running 100 meters (19 seconds), running 2 minutes, having a $14 \mathrm{~kg}$ burden and going up and down a 10 inch stool 5 minutes the pulse rate finally became about 2 times of that when standing up still. Also after these exercises the pulse beat took 20 minutes to become normal so climbing with only 10 minutes rest means that it had not got to normal before climbing again.

The production of heat is very large when climbing, but the surrounding condition makes it easy for the heat to radiate so the body temperature does not rise.

\section{SOME GHEMIGAL AGENTS EXGRETED IN SWEAT GONGERNING THE TEST FOR FATIGUE \\ KOREHIRO OGATA \\ Department of Physiology and Hygiene, Research Institute for Diathetic Medicine, Kumamoto University}

After perspiring, if a large amount of water is taken there is a large difference 
in the extra cellular liquid volume when measured by the thiocyanatedilution method and $\mathrm{Cl}$-space method. We thought that this was caused by the loss of the pigment in the sweat and started to examine the material excreted in the sweat. Actually we could not find any material objective to the reducing substance index and protein index. Ketoinol substances could be found in the sweat but was very little compared to that of the urine and wasn't parallel. Takeya and Kawada's reaction materials were sometimes $80 \%$ in the urine but even then they were only $1-2 \%$ in the sweat. With the Donaggio and Yamazoe's method no connection could be seen between the figure of the urine and sweat. Lactic acid is more in the sweat than the urine and in sweat it is excreted more in the beginning of the perspiration and is entirely different in the nature compared with that in the urine. Vakat's iodic acid reducing power is quite high in the sweat also but this figure is very unstable, for instance $\mathrm{O} / \mathrm{K}$ varies from $2-45$ in the same individual doing the same stress.

From the above results the mechanism of the excretion of substances connected with the fatigue reaction are entirely different between the sweat and urine and also we think the sweat has only a little meaning from the standpoint of metabolic substance excretion. Also the unstable figure of the thiocyanate-dilution method is not caused by the loss of the pigment in the sweat but is mainly caused by special stress agents in the body that variates the distribution of the body fluid contents.

\title{
19. MEASURING FATIGUE GAUSED BY MOUNTAIN GLIMBING IN MEN WITH PHYSICAL DEFECTS
}

\author{
M. KOBAYASHI, J. UMETSU. M. KAMEYAMA, \\ T.AIZAWA, K. ONOKI \\ Physiological Laboratory Tohoku University
}

On August 4 and 5 of 1955 we examined the amount of stress of crippled persons before and after climbing Mr. Zao. (1759 m)

Persons examined were 10 healthy persons (average 31.6 years) and 19 crippled persons. (average 31.6 years) Method of measuring was done mainly by Motokawa's electric flickering method and as for contrast we used the flicker method and inspected the subjective symptoms also.

Result :

(1) Electric flickering rate (S) was as the graph shows, before climbing the cripples, average was $22.92 \mu \mathrm{A}$ (S.D. $5.00 \mu \mathrm{A}$ ) healthy persons $27.63 \mu \mathrm{A}$ (S.D. $5.67 \mu \mathrm{A}$.) and the average figure after climbing was the crippled $41.97 \mu \mathrm{A}(\mathrm{S} . \mathrm{D} .9 .51 \mu \mathrm{A})$ with the latter being $40.44 \mu \mathrm{A}$. Both had before and after climbing a $1 \%$ peril rate and a significant difference was seen. But after climbing there was a difference of $5 \%$ in the peril rate between both which is a significant margin.

(2) The critical fusion frequency results were the same.

Crippled : 35.85 (S.D. 3.72) (before) ….31.29 (S.D. 3.65) (after)

Healthy: 39.14 (S.D. 2.09) (before) …34.71 (S.D. 1.98) (after)

(3) The subjective symptoms were examined in the next three catogory, physical, mental and sensibility symptoms. Before climbing between the crippled and healthy 
there could not be seen a significant margin statistically, but after climbing, a significant increasement could be seen and especially it was significant in the crippled persons.

Conclusion :

Fatigue due to climbing could be seen in both groups. But the electric flicker value and critical fusion frequency value showed a $5 \%$ peril rate after climbing but this is not a significant margin. When climbing the healthy persons were subjected to more stress but if these persons were all given the same conditions it can be presumed that the crippled would get more tired.

\title{
20. ON THE FLUGTUATION OF THE AMPUTEE'S RELATIVE METABOLIG RATE
}

\author{
M. TACHIKI
}

Department of Hygiene, School of Medicine, Nagoya University

What effect does the daily medical gymnastics have on the amputees admitted to the railway orthopaedic sanatorium. The author considered the relative metabolic rate of each of them in three periods : 1) When they were first admitted, 2) When they were treated for 3 months, 3) For 6 months, 4) For 9 months.

The amputees were divided into the following. (A) Below the knee 11, (B) Whole leg 6, (E) Both legs 6, (C) Whole arm 4, (D) One forarm 5, (F) Both arms 2, (G) One arm and one leg 2. The change of the relative metabolic rate is expressed by an exponential function in the following tests; In free walking stress test (A) $e=97.05$ $\mathrm{T}^{-0.029},(\mathrm{~B})(\mathrm{E})(\mathrm{G}) \mathrm{e}=0.459 \mathrm{~T}-100$. In the ergometer stress test $(\mathrm{A})(\mathrm{C})(\mathrm{D})(\mathrm{F}) \mathrm{e}=98.86$ $\mathrm{T}^{-0.010}$. In the walking test with a bucket of 6 liters of water $(B) e=101.53 \mathrm{~T}^{-0.018}$. In the above with 3 liters of water (E) (G) $e=100 \mathrm{~T}^{-0.036}$, (A) the below the knee amputees' rate at the end of 9 month is almost within the same limit as of that of normal persons. In monotonous gymnastic test, arm amputees $\mathrm{e}=100.65 \mathrm{~T}^{-0.020}$, leg amputees $\mathrm{e}=96.83 \mathrm{~T}^{-0.018}$. In the comparative test of a normal $\mathrm{limb}$ and its corresponding abnormal limb, the normal $\mathrm{e}=94.41 \mathrm{~T}^{-0.037}$ with the abnormal $\mathrm{e}=99.32 \mathrm{~T}^{-0.043}$. We could notice the gradual increase of the ability of the left over healthy limb. Healthy leg $e=98.57 \mathrm{~T}^{-0.016}$, bad leg $\mathrm{e}=100 \mathrm{~T}^{-0.029}$ and this shows that the bad leg became better with training. Either of these show that the bad limbs even though they lost the muscle ability once they could be acquired gradually by suitable physical instuction and became stronger. We observed this recovering process.

\section{STUDIES ON FATIGUE OF EYE MOVEMENTS}

\author{
M. IKAI, J. YAMAKAWA. \\ Department of Physiology, School of Medicine, Tokyo University
}

The research on eye movement is done by, mechanical, optical and electrical methods and it is known that the voluntary eye movement varies very much by 
reflexes. When the eye is closed and the eye is moved or when moving the eye without staring at nothing the eye moves smoothly, but when we are reading or looking at a straight line on paper the jerk movement super imposes on this. When jerky movement occurrs in these cases it is thought that it iscaused by fixation reflex. On the other hand when we stare at a moving object the eye movement is nearly smooth. This is because the fixation reflex induces the eye movement so that the jerky movement does not occur.

Luckiesh and Moss (1938) recorded the eye movement electrically when reading long and found that the number of jerky movement increased with the time. So we recorded the eye movement electrically after having following movement for a long time and investigated the various results according to the time.

Persons examined sat in a dark room covering their left eye with a cloth and staring at an object with their right. For recording of the eye movement we put the surface electrode on the outside corner of the right eye and the forehead and made a magnetic oscellograph through an amplifier. With this method the electric change could be seen with the eye movement and from the record we could see indirectly the eye movement. It is said that this mechanism comes from the electrical field in the tissues around the eye caused by the eye movement.

One optical target is set so when it moves from left to right in 60 seconds in the range of 60 degrees visical angle it reaches the end and appears in the left edge instantly. The persons examined were made to stare at the optical target from left to right and when the right edge was reached they were made to stare at the optical target which appeared at the left edge and this was done over and over. This was performed for about an hour. The persons examined where healthy adult men and women.

From the results of the experiment it can be seen that various changes occurred with the time. In the beginning the potential changes were rather smooth and this was repeated over and over. ( 1 time $/ 6$ seconds) This shows that the eye movement is smooth and we called this A type. B type is a jerky movement which can be seen on the smooth potential change and this means that the following of the eye became faulty. $\mathrm{C}$ type is the following movement broken in between and moved to the opposite direction rapidly and recovered to the following movement rapidly again. $D$ type is the movement which becomes entirely faulty and the eye movement stops at some unbalanced middle point by itself. This is seen when the fixation reflex becomes weak and the person becomes sleepy. In other words this is the omission of the following movement. $\mathrm{E}$ type is when the following movement is rather smooth but it is destroyed in between and recovers to the former place slowly. $F$ type is the ovey compensation of the following movement.

These types do not always come in one order, but B, C, E, types can be seen rather early and D, F, types comes after a moderate time has passed. After these changes sometimes A type (normal type) appear suddenly. Also because the fatigue of the eye muscle is small, it is thought that a large portion of this is caused by the disorder of the eye muscle nerve regulation or the decrease of concentration caused by simple labour much more than the eye muscle fatigue. 


\title{
22. STUDIES ON THE PHYSIC-CHEMICAL PROPERTIES OF THE SUBSTANCES FOUND IN THE FATIGUE URINE.
}

\author{
H. UEHARA \\ Department of Physiology, Kyoto University
}

I think that from Professor Sasagawa's "Basic Living Unit Body" theory we have come to a point where we can argue on the general secretion and excretion.

From the thought of finding a more direct and more objective way of reflecting fatigue in order to argue about the fatigue of the living body, I thought that even though from examining the urine the complicated process could not be measured but I could catch something that would correspond to the conditional changes in the living body. From this standpoint, from last year inorder to make a standard from the temporary fatigue to the accumulated fatigue, I have searched the urine from all angles. Inorganic matters were $\mathrm{Cl}$, and sulfanic acid, organic matters were amino acid, Donaggio's reaction and protein. Physical characters were refractive index, ph, etc.

This time like reported before, as a method to confirm if the change of the physical character of the high molecule matter in the temporary fatigue urine corresponds with the expectation of the "Basic Living Unit Body" theory, I have searched from the viscosity standpoint.

\section{STUDIES ON EXERGISE PROTEIN URIA (IV).}

\author{
A. KITAHAMA, Y. KITAHAMA \\ Tokyo University of Education, Department of Physical Education, Institute of Hygiene
}

We have made the following observations and studies on the regulatory albumin uria in field, track, swimming and ergometer of grammer school, middle school, high school and university students. Individually before and after exercises and during training camp we divided a day into 6 and saw the changes in the developement of regulatory albumin uria. Concerning the kidney function when regulatory albumin uria was present we inspected the following, kidney blood circulation condition, albumin uria per hour, urine volume per hour, ph, sedimentation, blood pressure, pulse, respiration, electrolyte clearance $(\mathrm{Na}, \mathrm{K}$.$) hematocrit, arterio blood$ gas, etc. We divided the persons into athletes and non-athletes and experimented them during and not during training camp.

In the kidney blood circulation volume, PAH clearance, GFR endogenic creative clearance, in albumin uria sulfo salcylic acid, Spiegler's method for qualitation, Kingsburg's method for quantitation, for electrolyte flame photometer were used.

The above results were : (1) When albumin uria could be seen during exercise RBF and GFR declined. After stopping the exercise the disapperance of albumin uria and the recovery to $\mathrm{RBF}$ and GFR was more rapid in athletes than non-athlete. (2) The kidney function when swimming or even when just staying in the water 
quietly the RBF and GFR decreased. After swimming strain everybody had albumin uria and RBF and GFR decreased. (3) When examining the kidney function from the standpoint of the renal blood circulation condition, regulatory albumin uria is caused by the kidney oxygen supply decrease and this increases the osmosis of the glomerus filter membrane. (The above has been reported at the 29 th and 30 th physical conference.)

Concerning the factor for the cause of regulatory albumin uria the surrounding condition, posture and the whole body influence is connected complicatedly. Among these, posture and the surrounding condition has been partly reported. This time we have experimented to see if shortage of oxygen supply to the kidney is caused by the decrease of kidney blood circulation or also if the oxygen density in the arteries has any influence.

(1) The problem of artery oxygen: After exercising stress of 2000-3000 kgm and $4000-5000 \mathrm{kgm}$ was applied and when artery punction was done, in 5 out of 6 cases the artery oxygen density had a tendency to increase a little.

(2) After swimming 500-800 $\mathrm{m}$ in 20 minutes a little decrease compared to before swimming was observed.

(3) In 8 cases a stress (ergometer) was given in 4 classifications under a constant condition and the artery blood oxygen saturation was measured by oxymeter before, during and after the exercise but no marked changes could be seen.

(4) Venous pressure: If various exercise stress is done over and over we must study the connection between the albumin uria and kidney venous pressure but we will leave this for animal experiments. There are reports by Kaneko, etc. saying with 100 mghg increase, albumin uria appeared.

(5) Exercise stress and kidney function: Dividing the exercise into 5 classifications and having rest in between and doing it over and over in the same day, or making them have exercise stress of one class per day for a few days, also having these persons swim, we inspected the regulatory albumin uria appearance, process, quantitative connection and kidney blood circulation condition (kidney circulation blood volume, glomerus filtering figure, filtering index), blood pressure, pulse, respiration and exercise volume.

From these results : (1) When changing the stress gradually daily made the exercise stress larger but had less effect on the kidney function compared with doing it over and over on the same day with a little rest in between. (2) Swimming stress is more than track and field and had more effect on the kidney. (3) If exercise stress is applied during the same day after a weak stress is applied and waiting for the disappearance of the albumin uria, and next if a strong stress is applied, albumin uria increases but the kidney function doesn't ratio with the strength of stress but it becomes lighter oppositely.

\title{
24. STUDIES ON EXERGISE PROTEIN URIA.
}

\author{
K. SUMIYOSHI, A. HAMADA, T. OMI, \\ T. IZEKI, M.SUMIYOSHI \\ Ist Internal Medicine Department, Osaka City Universtiy
}

We have examined the urines of some athletes up to $1 \frac{1}{2}$ hour after the games of 
various sports and searched for albumin uria reactions and urine sediments. We dyalysed, salt out and made the albumin into powder with our freezing drying divice, then made this into a certain constant concentration, was dyalysed 24 hours with veronal veronal sodium buffer fluid and using Tiselius divice measured the albumin contents by electrophorasis.

Results : Albumin Reaction; In boxing, 10000 meters and 5000 meters hardly nobody showed negative or very slight positive results but in marathon 4 out 10 these results could be seen and was more frequent in persons in the high ranks. In boxing and 800 meters albumin reaction was very strong and in all cases they were medium or stronger.

Urine Sediment; In marathon many red blood corpuscles could be seen but in 800 meters it was normal. Cylinders could be seen in every sports besides 10000 meters and were many in marathon. There could not be seen any characteristic differences in the sports concerning kidney epithels and white copuscles.

Albumin Uria Contents; Searching the albumin uria after sports by electrophorasis as is indicated in albumin uria of renal deseases, nearly all cases showed the blood serum albumin contents, albumin and globulin, $\alpha$-globulin and $\gamma$-globulin. The contents ratio differed according to the various sports. Albumin contents in boxing were $40-70.8 \%$ with the average $57.2 \%$. In marathon it was lower with $40.2-$ $50.8 \%$ an average of $45.2 \% .800$ meters showed a lower figure. $\alpha$-globulin contents were in boxing $5.1-9.5 \%$ and average of $7.9 \%$. In marathon it was $10.9-17.6 \%$ an average of $14.5 \%$ which compared to boxing was an average of 1.8 times. There was no significant difference in $\beta$-globulin contents according to the various sports. $\gamma$ globulin contents were the lowest in boxing $12.5-43.8 \%$ an average of $27.9 \%$. Marathon was a little higher with an average of $31.6 \% .800$ meters had the highest contents with 2 cases having $56.5 \%$ and $59.7 \%$. This needs to be studied further and there were two cases with nearly all $\boldsymbol{\gamma}$-globulin.

Next in boxing there was a very large difference in albumin and $\gamma$-globulin percentages individually. In albumin a 30\% margin and in $\gamma$-globulin a $32 \%$ margin could be seen. On the other hand in marathon the albumin figure and $\gamma$-globulin figure had only about about a $10 \%$ margin individually. This is smaller than the one mentioned before and no significant individual difference could be seen.

Conclusion: When we summarize our experimental results, the albumin uria in boxing showed a large albumin contents and $\alpha, \beta, \gamma$-globulin contents were small.

In marathon the albumin contents were smaller than boxing and $\alpha$-globulin contents increased remarkably, but a $\gamma$-globulin contents couldn't be seen.

In 800 meters the albumin contents were still smaller and $\gamma$-globulin contents were much higher than the 2 sports given before. But the cases were few so we must search further considering the kind of sports and the amount of exercise in the future.

\title{
24'. STUDIES ON EXERGISE PROTEIN URIA
}

\author{
NAGAO MURAKAMI
}

Department of Physiology, Mie University

Exercise protein uria can be roughly divided into two groups. (A) Temporary exercise protein uria. (B) Prolonged exercise protein uria. 
Cause: (A). 1) Kidney blood circulation decrease caused by the increase of the glomerus filter membrane osmosis. 2) Temporary increase of the filter volume of the glomerus membrane after exercise. 3) The increase of the serum albumin caused by exercise.

(B). This is caused by a supplementary substance (Histamine) doing the constant ischemia of the muscle. This is freely isolated in the blood and increases the glomerus filter membrane osmosis.

Therefore (A) (B) have entirely different causes.

\title{
25. STUDIES ON THE RELATION BETWEEN INTENSITY OF EXERGISE AND LACTIG AND PYRUVIG ACID
}

\author{
M. TSUBOI, M. ISHIMOTA, M. MINAMI \\ H. ASAKAWA, T. SEKI, H. SUZUKI \\ Department of Physiology, Tokyo Jikei School of Medicine
}

The ratio of lactic and pyruvic acid $(\mathrm{L} / \mathrm{P})$ during rest time is just about balanced, but the balance is broken by exercise, and the figure is rather large compared to the rest time.

Suzuki of our department has reported that from the investigation of the ratio of lactic and pyruvic acid during excercise, the ratio differs according to how the exercise is done, aerobic or anaerobic.

We have investigated further for the connection between exercise and blood L/P. We had 3 students use the bicycle ergometer in various stresses and measured the amount of exercise, oxygen demand, blood lactic and pyruvic acid.

1) The connection between the stress of the exercise and the oxygen demand is that two connection forms can be made, relatively aerobic and relatively anaerobic with the maximum oxygen intake as a border.

2) The increase rate of the blood lactic and pyruvic acid has entirely opposite increasing connections according to the relatively aerobic or relatively anaerobic exercises.

3) So the L/P right after exercise has, when the exercise condition was relatively aerobic, increasing connection and increased according to the stress of the exercise positively, but if the exercise becomes very severe and goes past the maximum oxygen intake this becomes opposite and increases negatively.

4) From these results the saccharine inter mediate metabolism changes characteristically according to the relatively aerobic or anaerobic excercise.

\section{STUDIES ON THE INFLUENGES OF PHYSIGAL FATIGUE UPON THE AMOUNT OF VITAMIN B, OF VARIOUS ORGANS Y. TAMURA, K. TAKADA. Institute of Physiology, Faculty of Medicine, Kyoto University}

1) Introduction: We are investigating the connection between the liver function 
and physical fatigue. We got our hint for this investigation when we studied the fatigue of swimmers in 1949. (Reported at the 27th Japan Physiological Conference, 1950) The next year with the import of methionine we made a fatigue recovery medicine with methionine as the main substance and studied it's effect. (Reported at the 4th Japan Physiological Conference 1951) These are the beginning on the study between fatigue and liver function. After this the liver function has been examined in many ways when the body was tired and found that it is obstructed to some extent. But the main cause of this liver function obstruction hasn't been examined thoroughly yet so as part of this study we have studied the quantity of vitamin $B_{1}$. On the other hand concerning the connection between exercise and $B_{1}$, it is known that it's needed but this is from experience and there is no accurate data. The liver and kidney has various functions in normal conditions, but when metabolism caused by the exercise occurs there seems to be quite a strong connection.

2) Methods Used: We have used rats in our investigations. We have used rats from the same mother with just about the same weight. We fed them unpolished rice and the stress was about 30 minutes swimming a day. The time of experiment was from September to October and the effect of temperature was neglected. This is because at the present time there is no accurate investigation concerning the effect of heat and vitamin $B_{1}$ waste. The material used were $l g$ of the liver and the whole kidney. The measurements of $B_{1}$ of the kidney and liver are all the total quantity.

3) Experimental Results : First to make sure that the average errors of the experiments were below $5 \%$ we performed preliminary tests.

It can be seen easily from the weight of the control group's labour stress that swimming 30 minutes a day for 7 days can result in fatigue.

The total liver $B_{1}$ quantity was in the labour stress groups compared with the control group, 8 out of 10 had marked decrease. (other two were in the average error limit) In kidney total $B_{\mathfrak{1}}$ quantity the labour stress group compared to the control group 7 out of 10 had marked decrease. (other 3 were in the average error limits) But the rate of decrease was smaller in the kidney than the liver.

4) Review: There are many reports concerning the connection between the liver function and $B_{1}$ but there is no report on the $B_{1}$ connection with the liver function which had changed because of exercise. But there are reports saying the sympathicotonic causes the decrease of the liver $B_{1}$ quantity and vagotonic causes the increase, and from our experiment we have found also that sympathicotonic causes the liver function decrease. Also there are reports saying that the liver $B_{1}$ quantity decreases when the thyroid gland function accelerates. Therefore when the metabolism is vigorous the liver $B_{1}$ quantity decreases and when it recovers the liver $B_{1}$ quantity increases. On the other hand there are reports saying that during exercise the blood $B_{1}$ quantity is increased. In other words it moves to the muscle logically and our $B_{1}$ giving test (Contrast and stress groups $100 \gamma$ per day for 7 days) also proves this. Therefore the liver works like a depot.

5) Conclusion : Exercise stress and $B_{1}$ giving tests with rats,

(1) Both liver and kidney total $B_{1}$ quantity decreases remarkably with exercise.

(2) Liver and kidney both have a depot ability for $B_{1}$. Therefore as a factor for the fatigue of the liver we can think about the depot ability. 


\title{
27. ON THE INFLUENGE OF PHYSICAL FATIGUE UPON THE LIVER FUNCTION (Report 8)
}

\author{
KEIJI TAKADA \\ Pepartment of Physiology, Kyoto University
}

In order to find out the connection of fatigue and liver function during physical exercise, we have made many liver function tests and have made reports accordingly. But trying to find the principle of fatigue we have been investigating the connection between the autonomic nerve tension and have reported the general principles up to our 7 th report.

This time we are going to report on how the prothrombin index and liver antidote function varies in fatigue.

We have used rabbits weighing about $2.0 \mathrm{~kg}$.

The method of exercise stress were acute fatigue caused by 30 minutes exercise stress and accumulated fatigue caused by 3 days consecutive stress.

The prothrombin index was measured by Quick's method using powdered brain and measuring the coagulation time.

In liver antidote function hippric acid method was used and the figures were from the $\mathrm{NaOH}$ waste volume.

1) Prothrombin Index:

Blood was taken 30 minutes, 60 minutes, 24 hours after normal stress.

Experimental results, review, conclusion : From the preliminary examination average error caused by taking blood could not be seen. Acute fatigue : In the average figure of 30 minutes after stress there is a little shortening $(0.2)$ in the time. In 60 minutes there is a little prolong in time. Accumulated fatigue : 30 minutes after stress there is a shortening in time as before but 10 minutes after the fatigue the prolong of time is significant. 24 hours later is shorter than 60 minutes but compared to normal this is prolonged. But this change can't be said to be a strong change from the standpoint of figures. The prothrombin index has the 4 factors for coagulation, prothombin, thromboplastin, calcium, and fibrinogen. Of these if the quantity of the first 3 is made constant it is said that the coagulation time has inverse proportion to the quantity of prothrombin. But it is said that if the living body is given fatigue as a stress the fibrinogen and calcium increases as a irritation reaction. From this the 30 minutes after stress figure makes sence. So it is not proper to talk about the liver obstruction with only the prothrombin index.

2) Liver Antitoxac Function:

The experiment was made 2 hours and 24 hours after normal time and after accumulated labor stress. $10 \mathrm{~g} / \mathrm{dl}$ sodium benzoium $2.0 \mathrm{cc}$ was used as a reagent and food was given 1 hour before the reagent was given. The 1 hour and 2 hours urine after the reagent was given were taken. The urine quantity and $\mathrm{NaOH}$ drop amount was measured. The result was, the amount of hippric acid excreation 2 hours after the stress was less compared to that of normal time. 24 hours after the stress, the amount increased more than 2 hours, but was less than the index of normal condition. There seems to be no connection between the quantity of urine and hippric 
acid excreation. The hippric acid method when kidney function obstruction is present the excreation volume is impedimented but concerning the liver function in fatigue there aren't any clear exeriments, but when in fatigued condition there seems to be some impediment in the liver antioxic function.

\title{
28. THE HOURLY VARIATION OF THE EQUILIBRIUM FUNCTION
}

\author{
MASAMITSU OSHIMA
}

The Institue for Science of Labour

As I have reported at the last conference I have examined 24 males who worked 24 hours for the hourly variation of the equilibrium function.

The unstable board test used was a round plate held up in the middle with springs on four edges so it moved back and forth and left and right. The person was stood straight on this plate and the back and forth, left and right movements were recorded individually and the equilibrium function was measured by the width and number of vibrations.

The following things were found:

1) Equilibrium function was worse when the eyes were closed and when the eyes were closed the left and right equilibrium function decreased in the day time and becomes better in the night and in the morning it became bad again.

2) When the eyes were closed there wasn't such a marked difference in the back and forth equilibrium function as the left and right equilibrium function but had the same tendency.

3) When the eyes were open the hourly variation of the equilibrium function didn't have a clear change as closing the eyes but had the same tendency.

4) The reason the hourly variation of the equilibrium function doesn't show a marked change when the eyes are opencd are, the benefit of the visual equilibrium function is large when the eyes are closed and the equilibrium function is bad, and when the eyes are closed and the equilibrium function is good it is small. So we can say that the benefit of the visual equilibrium function supplements the deficiency of the equilibrium function when the eyes are closed.

5) When we inspect the connection between the flicker value and the equilibrium function they have opposite relations except at the middle of the night. (2-5 AM) The flicker value starts to decrease in the evening but the equilibrium function when the eyes are closed becomes better. Also in the morning when the flicker value becomes better the eyes closed equilibrium function becomes better. But in the middle of the night the flicker value and eyes closed equilibrium function both change in the same direction and decrease and increase of the two make a valley like the graph shows.

6) As reported already 2-5 AM shows the lowest flicker value and this is the time when the living body has the most difference from the normal level. At this period the antagonism between the two oposite relationed rival function dissappears. This has heen reported before between the flicker value and tapping value. This can bs 
thought to be the same phenomina. The hourly variation of the equilibrium function which can be seen by the flicker value which is said to be the cortical function and the deep sensation which is said to be the subcortical function is I think a special characteristic of the movement of the living body function.

\title{
29. STUDIES ON THE RELATION BETWEEN EEG. AND MENTAL FATIGUE IN THE STALNESS (Report I)
}

\author{
KIYOSHI TANAKA
}

\author{
Institute of Physiology, Faculty of Medicine Kyoto University
}

Professor Sasagawa has proposed the classification of sever fatigue which appears after heavy practice is continued into three stages. Among these the third stage fatigue appears about one month after starting the training and also it is a established theory at the present that the mental fatigue factor of Leitenstolfer's classification has much influence.

Concerning this mental fatigue up to now experimental psycological investigations have been done, but there were many regrettable points from the experimental scientific side.

Recently from the experiments, EEG is becomming the object of fatigue measurement, so in order to make the change of EEG in the third stage clear we have done the following experiments.

We have taken people of the baseball team aged around 20 years with over 40 days practice, and examined the following things, 1) Took data on various questions concerning subjective fatigue symptoms, 2) Flicker test, 3) Measured the salve ph figure, 4) Donaggio's reaction, 5) ECG, 6) EEG.

The methods used were, for salve ph a ph meter, Donaggio's reaction with Sato's method, and ECG, EEG in a sealed room with the persons sleeping on their backs. The ECG was done by $1 \mathrm{mV}$, lcm vibration rates and recorded by lst, $2 \mathrm{nd}$, and 3rd leads as should be.

Also the EEG was done by $20 \mathrm{mV}, 1 \mathrm{~cm}$ vibrations and as an electrode with a $8-10 \mathrm{~mm}$ gold plate on the forehand, back of the head, forehand on contrast points with multipolar leads. In EEG as a dialysis method 1) $\sigma$-index measurement, 2) Average periodic, 3) Average vibration, 4) $\alpha$-index, 5) The continueing rate of the $\alpha$-wave was examined. But as a threshold of the $\alpha$-wave measurement it was made over $10 \mathrm{mV}$.

The results were; 1) The appearance of subjective fatigue symptoms, 2) Low flicker rate, 3) The appearance of fluttering of the ECG. Others were 4) In the EEG the forehead lead and forehead multipolar lead had much irregularity in the basial line and unusual $\sigma$-waves appeared, forehead multipolar lead had enlargement of vibration but from these things we found that we can use the EEG for the measuring of the mental fatigue in the third stage of fatigue period. We have not investigated the first and second stage of fatigue but we are planning to experiment on them to obtain many comparison factors. 


\title{
30. RELATION OF PHOTO-STIMULATION TIME TO REGOVERY TIME IN EEG (2)
}

\author{
M. MASUDA, M. TUGANESAWA \\ Department of Physiology, Jikei Medical School of Tokyo
}

When the light is shined in the eye the $\alpha$-wave of the electroencephalogram is suppressed. The suppressed $\alpha$-wave gradually recovers and appears again. The recovery time is said to be influenced very much by the mental condition. But when the first $\alpha$-wave group that appears after the $\alpha$-wave suppression is looked at thoroughly, a special feature can be seen. Naturally it is a little doubtful to use the word "the real recovery of $\alpha$-wave" for this $\alpha$-wave group. Also for this experiment there are many factors, the power of the light, the shining area, the shining time. Having the power of the light constant and only changing the light shining time, shining time T, $\alpha$-wave controled incubated time t, $\alpha$-wave control in other words the appearence time of $\beta$-wave $\mathrm{a}+\mathrm{b}$, the appearing time of $\beta$-wave which is divided by $\mathrm{T}$ is made $\mathrm{a}, \mathrm{b}, \mathrm{T}>\mathrm{t}$, the $\beta$-wave divided by $\mathrm{T}$ and $\mathrm{T}$ ratio $\mathrm{a} / \mathrm{b}$ has mutual relations like the graph. If the small points of the light time is avoided it appears as a continual function.

We have tried to find a special feature in the irritation of the cerebral cortex in exercise by investigating the change of influence of the stress (exercise) on the regularity obtained by only the light shining condition. So we have recorded the electroencephalogram and the motor reflextion time of the forearm muscle at the same time and tried to find some connection caused by the motor system supplement. When the most simple motor reflex of the conscious movement is used as a stress both mutually related straight lines extent and the angle $\theta$ of the recurrence line becomes large. In other words the increase percentage of $b$ enlarges. The difference between these two correlated lines can be regulated by irregulated numbers $\mathrm{T}, \mathrm{a}$, and $b$. When the exercise stress and non-stress records are put on each other, there is a possibility of 2 out of 3 that the irregulated numbers might coincide. If $T$ and $\mathrm{a}$ in other words $\mathrm{T}$ and $\mathrm{T}-\mathrm{a}$ or $\mathrm{T}$ and the incubating time of the $\alpha$-wave suppression $t$ is the same the activity of the motor system enlarges $b$. If $a$ and $b$ are constant under the motor stress the light shining time $\mathrm{T}$ must enlarge. Also if $\mathrm{T}$ and $\mathrm{b}$ are constant the motor stress a gets smaller. In other words this means that the incubation time of the $\alpha$-wave suppression gets longer. From these facts under these two conditions, it can be thought that the character of the incubat: on time of the $\alpha$-wave suppression varies and from this it can be considered that the motor stress, the $\alpha$ wave has connection with the motor system.

Also when we investigated the $\mathrm{T}<\mathrm{t}$ condition, we found that the $\alpha$-wave divided ratio caused by $\mathrm{T}$ and $\mathrm{T}$ has a mutual straight line connection. But between the motor stress and non-stress we found a opposite correlation. But this investigation is only a forecast report. 


\title{
31. ELEGTRONIG MYGROSGOPIG STUDIES ON MUSCLE FATIGUE
}

\author{
Y.TAMURA, Y.NABEJIMA, Y.MORI. \\ Department of Physiology, Kyoto University
}

Concerning the skeletal muscle, Hosomi, Nabejima, etc. have made the following cognition facts accurate with the electronic mycroscopic investigation. The dark and light zones come alternately and form the horizontal stripes and at each place, Z. N. M. H. etc, zones exists. Before the electronic mycroscopic investigation, there were many reports concerning the relation between the stripe structure and muscle contraction but there is no precised understandable muscle theory or fatigue theory based in the premise of inocomal hypothesis status. Beside this there is no morphological investigation on how the changes occur in the fatigued muscles. Therefore, last time the peroneus muscle of a bull frog was taken out and searched for the changes in the fatigued muscles electro-mycroscopically. The peroneus muscle is easy to take out and very convenient in the process of irritation, but the fibers run obliquely and the muscles were fat so was hard to fix it as a contract to electromycoscopic investigation, so the sartorius muscle was used. As material we took both sartorius muscles and gave irritation to one side once very 4 second, with direct electric irritation until the muscle didn't contract anymore (after this we will call this the fatigued muscle) and was pinned to a splint fix in $10 \%$ formalin physical salt water over 24 hours, then was crushed in a glass homogenizer. The other contrast muscle was processed in the same manner. The following results were obtained.

1) The length of muscles segments were, fatigued muscles $2.72 \mu$, contrast muscles $2.52 \mu$. The fatigued muscles were $0.02 \mu$ longer.

2) Light zone were, fatigued muscles $0.96 \mu$, contrast muscles $0.89 \mu$, The fatigued muscles $0.07 \mu$ longer.

3) Dark zone were, fatigued muscles $1.76 \mu$, contrast muscles $1.63 \mu$. The fatigued muscles $0.13 \mu$ longer.

4) Dark and light zone ratios were, fatigued muscles 1.91 , contrast muscles 1.86 . Very little difference could be seen.

5) The $\mathrm{N}$ and $\mathrm{H}$ zone which were said to have relations with muscle contraction, $\mathrm{N}$ zone fatigued muscles 3 cases and contrast muscles 5 cases, $\mathrm{H}$ zone fatigued muscles 8 cases and contrast muscles 6 cases. The length were, fatigued muscles $0.2 \mu$ and contrast muscles $0.18 \mu$ with $0.05 \mu$ difference.

In order to be able to say that the above fatigued results were caused by fatigue, we must make sure that with the same objects these things will not occur with only one or two muscle contractions.

1) The muscle segment length when irritated, both showed $3.19 \mu$ and no change could be seen.

2) Light zone irritated muscles were $1.30 \mu$ and contrast muscles were $1.90 \mu$ with very little difference.

3) Dark zone irritated muscles were $1.89 \mu$ and contrast muscles were $1.90 \mu$ with hardly any difference. 
4) Light and dark zones ratios were, irritated muscles 1.46 and contrast muscles 1.48 with very little difference.

5) In $N$ and $Z$ zone which is said to have connection with muscle contraction, $N$ zone irritated and contrast muscles both had one case, $\mathrm{H}$ zone irritated muscle had 3 cases and contrast muscle had 2 cases. Length of fatigued muscles were $0.28 \mu$ and contrast muscles were $0.3 \mu$.

When we review the results of the muscle segment length, when electric irritation is applied to the sartorius muscle, muscle segment length, light zones and dark zones are all longer in the fatigued muscles compared with the contrast ones. The muscle segment length change is due to about the same increase of the light and dark zone. Also with little irritation these can't be seen so I think there is no objection in saying there changes are caused by fatigue. The thing with special interest is the $\mathrm{N}$ zone which has deep connections with the muscle contraction and when the muscle is fatigued we have found that appearance of $\mathrm{N}$ zone cognition is not thorough.

\title{
32. STUDIES ON THE HEART OF ATHLETES REPORT 1. EGG FINDINGS
}

\author{
E. HISAMATSU, A. KOBAYASHI.
}

Chuo University

Concerning the heart enlargement of athletes it has been explained as ventricular hypertrophy, sometimes dilatation is added and the cause had been said to be elastical dilatation, but recent investigations have named this controllable dilation and disavowals the unreversable hypertrophy (organic) dilatation theory.

We have taken the E.C.G. of 245 athletes of Chuo University (field, track, swimming, wrestling, sumo, rugby) and investigated the existance of hypertophy of the right and left ventricula and the general findings.

First we investigated the existance of the right ventricular hypertrophy from $V_{\text {, }}$ lead $R / S$ value, $R$ absolute value, approaching effect, from $T$ potential $V_{2}$ lead, and divided these into 4 groups, $R / S$ value under 1 (normal value), $1-1.5$ (doubtful value), up to 3 (pathological value), over 3 (hypertrophical value). Each group was divided into two groups again, the $\mathrm{R}$ value below $0.7 \mathrm{mV}$ (normal value) and over $0.7 \mathrm{mV}$ (abnormal value). Approaching effect over $0.04^{\prime \prime}$ was considered delayed. When $V_{1}$ QRS showed $r s R^{\prime}-r s R^{\prime} s^{\prime}$ type it was considered right bundle branch block. Of the 81 field and track athletes, the results were, $\mathrm{V}_{1} \mathrm{R} / \mathrm{S}$ normal value 76 (in which $\mathrm{R}$ abnormal $50 \%$ ), doubtful value 4 , hypertrophy value 1 ( $R$ all abnormal value, approaching effect delayed 2), $\mathrm{V}_{2}$ Tvalue $\mathrm{O}<\mathrm{T} \leqq 1 \mathrm{mV}$ group and $1<\mathrm{T} \leqq 2 \mathrm{mV}$ group about half and half. Of 36 swimmers, $V_{1} R / S$ normal value 34 (in which $R$ abnormal value $41 \%$ ), doubtful value 2 (both $R$ abnormal value with delayed approaching effect), $\mathrm{V}_{2} \mathrm{~T}$ value $\mathrm{O}<\mathrm{T} \leqq 1 \mathrm{mV}$ group and $1<\mathrm{T} \leqq 2 \mathrm{mV}$ group were about half and half. Of 78 rugby players, $R / S$ normal value 71 (in which $R$ abnormal $41 \%$ ), doubtful value 3 (all $R$ abnormal, 2 delayed approaching effect), right bundle block type 4 cases, $\mathrm{V} \mathrm{T}$ value $\mathrm{O}<\mathrm{T} \leqq 1 \mathrm{mV}$ group $51 \%, 1<\mathrm{T} \leqq 2 \mathrm{mV}$ group $42 \%, \mathrm{O}>\mathrm{T}$ group $7 \%$. Of the 27 wrestlers $\mathrm{R} / \mathrm{S}$ normal value 25 (in which $\mathrm{R}$ abnormal $40 \%$ ), pathological 
value $\mathrm{l}\left(\mathrm{R}\right.$ abnormal value), $\mathrm{V}_{2} \mathrm{~T}$ value $\mathrm{O}<\mathrm{T} \leqq 1 \mathrm{mV}$ group, $\mathrm{l}<\mathrm{T} \leqq 2 \mathrm{mV}$ group were about half and half. Of the 21 sumo wrestlers, $R / S$ all normal value ( $R$ abnormal $38 \%$ ) $\mathrm{V}_{2} \mathrm{~T}$ value distribution had no marked change.

The existance of left ventricular hypertrophy was examined by the existance of $\mathrm{V}_{5} \mathrm{~T}$ value, QT time extension, and left precorial lead ST, T changes. No marked changes in $\mathrm{ST}$ and $\mathrm{T}, 5 \mathrm{QT}$ time extension, no reversal of $\mathrm{V} \mathrm{T}$ value, when each group was analysed it was $\mathrm{O}<\mathrm{T} \leqq 0.5 \mathrm{mV}, 5-23 \%, 0.5<\mathrm{T} \leqq \operatorname{lmV~} 18-42 \%$.

Concerning the right ventricula the results of $V_{1} R / S$ value and $R$ value didn't match but the age variation was 18-24 years so concerning $R$ value the objective cases must be inspected. The approaching effect doesn't always match the other observations. Left ventricular dilatation was seen in only a few cases. The $V_{1} R$ value increase was rather large in the track and field athletes. Other observations were, PQ extension 21 cases, second degree auriculo-ventriculo block 1 case, auriculo-ventriculo separation 1 case, myocardio insufficiency 3 cases.

\section{STUDIES ON THE NATURE OF THE TREMBLE OF E.G.G. IN FATIGUE (Report VII)}

\section{SUSUMU TANAKA}

\section{Institute of Physiology, Faculty of Medicine, Kyoto University}

Sasagawa discovered that a tremble appears in the E.C.G. when fatigued. This investigation has been continued by his understudies and has been established that it's essential is skeletical and not muscular, but there are many unknown factors. This time we have performed this experiment to investigate the point of appearance and time of appearance of this tremble thoroughly.

We recorded the two leads before and after the stress together from, ear-right hand joint superior side, ear-left hand joint superior side, and ear-left foot joint superior side leads. This was done to find the existance of electric discharge in the right hand, left hand, and left foot.

Next the leads were made from the left hand joint superior side, the contraction side of the thigh (Biceps femoralis skin), the extension side of the thigh (Quadricepts femoralis which is considered to have the most connection with the bicycle ergometer stress).

In the former we used persons from our department and each person turned a $3 \mathrm{~kg}$ stress for 10 minutes at a speed of 1 turn per second. For the latter we used 5 students each with a $4 \mathrm{~kg}$ stress for 60 minutes.

When we summarized the above experiments, the tremble is less right after the stress and appears about 20-60 minutes later. It is a fact that even though there is hardly any stress on the arm it appears the same as the leg.

This exphasizes that the substances made at the place of the stress goes to the rather rested places through body fluid and it can be interpretted that the two factors which will be given later causes the tremble.

First as a cause of the appearance of tremble during the disposement process of the tissue cell protein which can be said to be a metabolic product or fatigue factor 
appears in the body fluid and makes a difference in the lead electric potential.

The next factor is the abnormal disposement substance made at the stress area which is sent to the rested body area through body fluid and a change comes in the body fluid structure at this area. This directly or reflectionally works on the muscles and results in the tremble.

Also in the leg, right after the stress the appearance of the tremble is small and looks a little mysterious but it takes some time for the substance that makes the tremble to have effect on the living body.

When we summarize the above, by muscle labour a chemical substance developes making a change in the body fluid contents. This not only is carried to near places but also to distant places and the two factors given before causes the tremble.

\title{
34. THE EFFEGT OF ADONA ON THE FATIGUED BODY (Report I)
}

\author{
YOSHINOSUKE TADAI \\ Institute of Public Health
}

From the working point of Adona a blood stabilizer used clinically, we presumed that this had the effect of lightening the physical stress of statical heavy labourers, in other words stress mollifying effects and picked 20 stevedors for our experiment. We gave them Adona and fake medicine pills and inspected the effect on the fatigued condition when working for a period of two weeks.

First we divided them into two groups of 10 . For the first and second week from Monday to Thursday (4 days) we gave each group Adona ( $15 \mathrm{mg} /$ day) and false medicine alternately, from Tuesday to Thursday ( 3 days) we inspected the pulse and breath stopping time when standing and lying down. Also on Tuesday and Wednesday ( 2 days) we counted the eosinophilic leucocytes. With these we also recorded their feeling.

When we estimate the analyse of these measured figures there could be no promising changes in breath stopping time, but the pulse rate when standing especially the low rate after labour and from the difference between the eosinophile leucocytes before and after work, it can be estimated that there is deffinately a stress mollifying effect on the muscle labour in Adona. The effect of Adona doesn't continue even though it is given everyday. Also there was a marked difference individually.

\section{AN EXPERIMENTAL STUDY ON THE REGULATING MECHANISMS OF BODILY NEEDS. Report II. DRINKING BEHAVIORS AFTER THIRST OR MUSCLE MOVEMENT.}

\author{
Y. KAWAMURA, S. NAKA. \\ Department of Physiogy, Dental School, Osaka Universtiy
}

At the present there are still many unknown points concerning the physical mechanism of regulating the water absorption behavior. The main principles of this 
experiment was to find the external and internal factors concerning the water absorption behavior of animals. As shown on the drawing we designed a apparatus to record the drinking and urinating behavior of rats. This divice utilizes the spring balance principle and the quantity of water absorption is recorded on a kimography which rotates once in one hour, through a lever according to the contraction of the spring.

Normally a rat drinks water during the night and we examined 9 rats 18 times during the summer and the daily average water intake was $15 \pm 7.8 \mathrm{cc}$, the daily drinking frequency being $28 \pm 10.8$ times. After 48 hours of water abstain, at first a large amount of water was taken. The daily water intake increased remarkably with an average of $26.5 \pm 10.3 \mathrm{cc}$. But the frequency of drinking didn't increase very much $32 \pm 16.2$ times. In other words the water intake of a single time increased.

The animals mentioned above are in normal conditions and when vagotonized the absorption volume and frequency had a tendency to decrease while when the adrenal cortex was taken out the absorption volume and frequency both increased (water was $0.9 \% \mathrm{NaCl}$.) With a large area of the brain cortex cut out some amount of absorption behavior control could be seen. In compulsory swimming both volume frequency of water intake had a tendency of decreasing. With compulsory movement by harmful irritation on the foot fingers, the daily water intake increased.

From the above results we considered that an animals' water absorption has its function in the corpus of the brain and the humoral agents of the hypophysis and adrenal is very important but we can't neglect the brain cortex function.

\title{
36. EFFEGT OE TRAINING ON SIMPLE MOVEMENTS (Report III)
}

\author{
T. HARADA, Y.AISO. \\ Department of Physiology, School of Medicine, Toho University
}

I have reported twice on the practicing effect on simple movements. The experiment this time is for the same purpose as the former reports but the more complicated movements were continued for a certain period and the practicing results were investigated. This method is a fixed standard line drawn on a roll paper and moved at a fixed time. The hand was fixed with the finger pulling a string which moved the brush and made it trace the standard line. The practicing condition was once a day, the length of the roll paper 2.5 meters and rotating once a minute. The first time was written on roll paper and the next three times was practice and the forth time was written on the roll paper again. In other words the standard line on the roll paper was traced five times and the beginning and the end was recorded. This was the daily amount of practice and the practicing schedules were the same as the first and second reports, 2, 3, 4, 5, 6, days consecutavely, 1, 2, 3, 4, 5, 6, days rest and over 7 days rest, and there were combinated adequately with the one month schedule. The practicing effect judgement was made with the area between the standard line and traced line and measured by a planimeter record as $\mathrm{cm}^{2}$.

When this movement was done on a continuous schedule the langer it was continued the better the results became. 
Next with rest interval schedules, 2 days rest had better results than a day rest, 3 and 4 days rest had better results than 2 days rest, but when rested over 5 days the results became bad. Therefore the movement had better results with 3 or 4 days rest intervals than 1 or 2 days interval.

Next concerning the practicing effect and body temperature, the mouth temperature was taken, before, during and after the movement. From this it seems that the mouth temperature was a litte lower when the results became better than the early part of the schedule. Therefore in the beginning of the schedule when the results were not to good the mouth temperature was higher than the time the results were good, so it seems that the mouth temperature does not rise because of the metabolism of this kind of small movement but because of the stimulation of the center (nerve). We think when the results get good and experienced in the movement, the stimulation of the center does not occur and the mouth temperature doesn't rise. Cases with the same results, before, during and after the movement, the mouth temperature doesn't decrease during the movement so it seems that the center is stimulated always. We will experiment and report again on the connection between the body temperature and practicing effect more minutely.

As the conclusion, in this experiment the longer the movement is done continuously the results get gradually better. If rest intervals are put in, it becomes better with 3 or 4 days rest than 1 or 2 days rest, and if the rest is 5,6 , or 7 days the results become poor again.

\title{
37. ON THE LABOUR IN THE FISHER WOMEN (Report I)
}

\author{
T. TSUBAKI, M. NUKADA. \\ Laboratory of Physical Education, Toho University
}

Location of Experiment and Labour Period:

Shimagun Mie Prefecture, Late. $37^{\circ} 16^{\prime}$ N., Long. $136^{\circ} 54^{\prime}$ E. Period of labour was in the latter part of February to October, with 75 rainy days, and before and after cloudy and stormy days there were high waves and sudden change in current which caused the sea to become dirty and the labour was impossible so there were only about 15 workable days in July and August when little rain was seen. There was about 150 workable days during the closed season period. Like this year with very little rain and the goal is obtained they quit before the season is over.

Classification of the Fisher Women According to Their Work :

We divided the labour status of the fisher women into 3 classes. They are Oisobito, Nakaisobito and Koisobito. The Nakaisobito and Koisobito are sometimes called Isobataama. Oisobito (Funabito-ama) usually goes out in couples and the diving is done in $8-12 \mathrm{~m}$ depth, but the submerging depth due to the out-haling breath is limitted to about 7 meters so a high collar anchor is used as a submerging support. It takes 10-15 seconds to reach the bottom of the sea and then they let go of the anchor and work in the water and when they out-hale as much as possible and have trouble in breathing they Signal to the person on the boat who helps her come up.

Oisobito and Nakisobito, who's special occupation is dive fishing, work about $6 \frac{1}{2}$ hours daily with 4 hours actual labour. Investigating their daily schedule they get up at 4.30 which is the same as farmers and go to the beach at 8 with the first 
labour 9-11, second labour 1-3 and third labour 4-6 and staying till 8 . The time besides working they get warm and recover from fatigue. (The above investigations were done in August)

Submerging Time and Respiration Regulating Time:

Our investigation was done during the Tengusa taking season and this can't be said to be the maximum submerging time but I think there is not much difference.

The fisher women of case No.7, submerged 53 times with the total labour time was 41 minutes, respiratory regulating time 57 minutes, the labour time was always the same but the respiration regulation time was 1.7 times of the first time. The maximum submerging time was 54 seconds with average being $45.6 \mathrm{sec}$. Also the fisher woman with a lung capacity of $3900 \mathrm{cc}$ had a maximum submerging time of 75 seconds, fisher women who had to quit because of cold the labour time decreased and the respiration regulating time became double. Up to now the fisher women submerging time was said to be $2-3$ minutes but from our investigation 80 seconds was the maximum.

Lung Capacity:

People who have measured before said there wasn't much difference between the ordinary persons but from our investigation Oisobito averaged about 2850cc and decreased with the age. The average of the fisher women up to 40 years was $2900 \mathrm{cc}$ with the maximum figure being about $3900 \mathrm{cc}$ at the age of $35-39$. Compared to farmers who fished mainly as a side business the lung capacity was larger with the average difference of $1000 \mathrm{cc}$.

\section{Blood Pressure :}

Maximum blood pressure increase could be seen in only 1 out of the 23 with the others decreasing. The blood pressure after work is said to rise and it is thought to be because of the change inside the body or acute fatigue, in other words, heart and respiratory fatigue, but this problem remains to be looked into. Compared to the maximum blood pressure of Japanese (Watanabe) up to 45 years, the average is higher but past this age it is $20 \mathrm{mmhg}$ lower. The decrease after work is larger in fisher women with high blood pressure and a 67 year old fisher woman had a decrease of $60 \mathrm{mmhg}$. From the results the blood pressure decrease rate was larger according to the age.

Flicker Rate :

The flicker rate decreased after work but with an hours rest it recovered compared to after work. But they started to work before recovering up to the standard of before the work.

Sulfosalcylicacid Test :

Out of 15,11 were positive and one was positive before the work. 3 were negative.

\section{2 OR 3 PROBLEMS CONGERNING THE MEASUREMENT OF THE BODY}

\section{HACHIRO HASEGAWA.}

Department of Physical Education, Yamanashi University

Concerning the measurement of the human body, especially the morphological measurement method, there have been many arguments about aninternational stand- 
ardization. From the standpoint of anthropology, at the many international conferences, the international agreement was made. In America the American Anthropometric Conference became the leader and constructed the Anthropometric Committee and worked energetically. In Japan also mostly the anatomists got together and investigated the standardization of the measuring of the human body (1946).

When standardizing the method of measuring, logical stand point is the most important but the practical points must not be forgotten. At the present we are still having trouble with the unstandardized measurements and have much trouble making the investigations. From the stand point of health and physical education, we have performed various tests and measurements, and in using these results not only from the morphological side but we have profitted very much by the standardization of the measurement method of many functions.

In standardizing the measuring methods there are many problems to be investigated yet. For instance, 1) Periodical changes caused by the time of measuring, 2) Method of measuring, 3) The number of times of measuring, 4) What to do with the measured results, etc. So we have taken 2 or 3 of these measurement articles as material and the historic background and the problems with it and look at these optimistically.

There are many theories on what time of the day the persons height should be measured, but it seems that the 10 AM theory is the most prominent. The reason for this is that the daily average height is the height measured at this time. Investigating the daily and weekly differences minutely this opinion does not fit. The variation of the time makes much difference, for instance, just after getting up or after resting in bed for a long time. Concerning gripping power, there are similar reports but it is not clear. Iinvestigated 21 university students and the results were as expected, low in the morning and gradually getting higher in the day and becomming lower in the evening but marked difference couldn't be seen. Concerning the leucocytes changes during the day, there are many domestic and foreign reports but they don't always match in time and quantity. I investigated on 3 university students for 24 hours and the results were minimum in the morning and maximum in the evening. (average increase 50\%)

The way of measuring the height is standardized the most among the items measured, but there are still many problems to be considered yet. The existance of a pole, the amount of extention of the neck, the method of holding the height scale vertically and the difference in breathing are the problems. I have made a height scale from the physical athletic standpoint and have had good results. In the measuring of the lung capacity there are many problems of breathing abdominally or thoratically. It has been reported in England quite a while ago (Sewalt and Pollard 1890) that, thoratical breathing is larger than abdominal breathing and the normal lung capacity measurement is smaller then the lung capacity of the thoratical and abdominal breathing put together. In Japan (Hasegawa 1926) there is a similar report. Actually if it is necessary to think about these factors in measuring the lung capacity, than my investigation is still a problem. It takes a lot of experience to differentiate these two and when they are conscious and a untrained person blows, the result is larger than blowing naturally or shows a larger figure faster. The measuring of the height is done usually once, but some people claim that it should be 
measured at least three times and the maximum or interim should be taken. (Daverport 1937, etc.) The number of times to measure the lung capacity is most argued about. (R. Martin, 1914-1925, Terada, Yagi, Ishikawa, ect.) From recent experimental results it has been proposed to be measured at least five times taking the maximum (Watanabe, 1953) or ten times taking the maximum and multiplying it 1.1 times. (Hasegawa, 1952) Concerning this recently in England (J.N. Mills etc, 1949), the causes and factors that cause the variation in the lung capacity figure is being investigated which seems very interesting. From the practical standpoint, it is desirable the least the measuring frequency is possible and to standardize the number of time of measuring.

\title{
39. PHYSIQUE AND NATURAL LIFE SPAN
}

\author{
K. HIRATA, H. TOMOHARI
}

Hirata's Institue

\section{Introduction:}

We wonder if there is any relation between physique and natural life span? If there should be, it is a very interesting and an important problem to find out what type of physique live long, but this is not solved thoroughly.

We tried to solve this problem and examined 4374 students who entered the grammer school in the Hamamatsu area from 1905-1914. (10 years) We examined the physical condition in the sixth grade and then the later physical changes and compared the physique of a portion of the living persons with the sixth grade physique. Also concerning the old peoples physique and health we went to the old peoples home and investigated. Using Hirata's Physique Vicissitude Grasping Method, we obtained the following interesting results.

\section{1) The Physique of the Dead:}

Persons entering between 1905-1914 were 47-56 years old by December 31, 1954. Among these 2870 were living, 1027 dead and 483 unknown. From the dead we neglected the war death, war sick death and accident death. We classified them by the disease and made a graph.

From the graph it can be seen that the majority of the dead had large growth skinny physique. Especially mental, digesting system and lung disease had a marked tendency of the skinny. Therefore the well growth skinny type, in other words, the city type physique seems to be a disadvantagious physique to maintain life.

Next when we inspected the dead and living distribution on the graph, we found the largest mortality rate in the large growth skinny persons and the smallest mortality rate in the standard physique typed persons. There was a mathematical promising difference.

2) The Physique of a Sixth Grade Student and Adult:

Up to now we have talked about the standard physique of sixth grade grammer students, but we next inspected how much of the physique of the sixth grade student can be seen in an adult. 
Some scholars say that the physique of children have much difference on the growing proccess individually so it does not have much importance in estimating the adults physique, but when we inspected the physique of 50 adults who came to be vaccinated and compared it with their sixth grade physique, the majority (over $70 \%$ ) showed less than 16 change. In other words over $70 \%$ are ruled there whole life by their sixth grade physique so it can be understood how important the physique of the infant and children is.

3) Old Age Person's Physique and Health:

We inspected the physique of 8 old people's home with a total of 543 persons in Shizuoka and Aichi prefecture and also from the observation of the head doctor we had them divided.

(1) Inspite of old age works energetically.

(2) Normal

(3) Very dull and tottering.

Conclusion :

From the above results the physique of the sixth grade grammer school student continues through the whole life usually. Large growth skinny type persons have a disadvantage concerning the maintenance of life and many die of lung, digesting system and mental diseases. Fat old persons have pep, which has become a know fact. In other words as a whole a fat person lives longer than the skinny person and this contradics the life insurance company of America's investigated results.

This report concerns only 4374 persons around Hamamatsu so we must not come to a conclusion that this is right. We plan to continue this investigation so we appreciate everyone's cooperation.

\title{
40. STUDIES ON THE APPRAISAL OF PHYSIQUE AND BODY TYPE BY THE TRIANGULAR SCHEME METHOD PART 1. STUDIES ON THE PHYSIQUE AND BODY TYPE OF TOHO UNIVERSITY STUDENTS.
}

\author{
S. YOKOBORI, F. SUZUKI \\ Department of Public Health School of Medicine, Toho University
}

In judging the physique and body type of a human being, there are Rohrer's coefficient and many other exponents. These exponents express the growth rate of the height, weight and girth of the chest, but is not sufficient in expressing the body type characteristics. Our senions Kretschmer, Sigaud, etc. have tried to classify the body type into many classifications, but these not only have physical morphorlogical measuring methods but many objective observations. In these classifications there are interism types and actually the classifications usually have difficuties. Recently in America, Sheldon took into consideration the entoderm, mesoblast and ectoblast factors and took pictures of students between 18-21 years under a certain constant condition, made measurements of 17 parts of the body from these pictures and from 
these figures classified body types objectively, and made a graph of these factors. Cureton changed this method a little by dividing the growth rate of the subcutaneus fat, muscle and bone by inspection and palputation into 7 stages, and by inserting this into the triangular scheme method, classified the body type into 10 . We made this method more simple and measured objectively by using equipmets. Subcutaneus fat by the cheek, abdomin by a ruler, muscle by measuring the hardness of the biceps brachii and gastrocnemius using Konno's hardness scale, bone by measuring the distance between the small head of the ulnar and radius at the hand joint and the distance between the malleolus fibularis and tibialis at the ankle. The variation and average of these measurements were obtained and the measurements were divided into 7 stages and by grouping these figures we tried to classify the body type. Forinstance, 171 is the muscular type (mesomorph) located at the apex of the triangle, 711 is the fat type (endomorph) located at the right corner of the triangle and 117 is the nervous type (ectomorph) with the worst muscles and bones and located at the left corner of the triangle. The results of the measurements of the male students of the Toho University by this method were, medial type with the 3 factors average $28.02 \%$, mesomedial type $16.81 \%$ and only 2 fat type persons. Female students were, mesomedials $29.65 \%$, medials $29.17 \%$ and no endomorph type.

\title{
41. STUDIES ON THE APPRAISAL OF PHYSIQUE AND BODY TYPE BY THE TRIANGULAR SCHEME METHOD PART 2. STUDIES ON THE PHYSIQUE AND BODY TYPE OF TOHO HIGH SGHOOL STUDENTS.
}

\author{
S. YOKOBORI, F. SUZUKI. \\ Department of Public Health, School of Medicine, Toho University
}

By the method of subject 40, we examined 114 Toho High School male students and the results were mesomedials $25.44 \%$ and medials $33.33 \%$ with no endomorths.

In 242 female students ectomedials were $28.10 \%$, medials $19.83 \%$ and ectomesomorphs $11.16 \%$. Ectoendomorphs were relatively large with $10.33 \%$. There were no endomorph types.

The characteristic features of the above methods are:

1) The structure factors of physique and body type, subcutaneus fat, muscle and bone growth ratio can be exprssed simply mathematically by considering the embryological factors.

2) The individuals' body type and physique can be located on a body type triangular graph.

3) Up to now the body type classification was classified into only about 3-4 types and was difficult to judge the middle type, but with this method it can be classified into 10 types including the middle type.

In the future we would like to investigate by this method the occupational class distinction and athletes. 


\title{
42. CONTINUAL OBSERVATION ON THE PHYSICAL GROWTH OF SCHOOL-GHILDREN, ESPECIALLY ON THE INFLUENCES UPON THE PHYSICAL EDUGATION (3rd Report)
}

\author{
TOSHIRO IZAWA.
}

\author{
Yokohama University, School of Medicine, Department of Orthopedic Surgery
}

The growth of physique and physical strength has besides individual variations, many variations according to the age and sex. Especially the grammer school period is one of the stages that body growth is the most vigorous, so the efficient physical education during this stage has much influence on the individual's future physique and physical strength. Also it is the same concerning the posture. Since 1953 I have made many measurements and observations continueously of the same class children at the Yokohama City Makado Grammer School. This time I will report on the main results of the last three years, and we have divided the classes by the condition of the physique and physical strength this new semester so I will also report on the yearly difference of growth during each perid.

1) The Transition of Body Growth:

Looking over the average body measurements of the last three years according to the sex, the height and sitting height are much higher than the national average in both sexes, in weight the boys are a little below and the girls are just about the same as the national average, the chest girth is about the same in both sexes. The difference between the sexes couldn't hardly be seen except in the chest girth. The chest girth statistically had difference, with the girls being larger than the boys, but the difference is becoming less yearly. Next the athletical ability, in running the sexual difference is decreasing yearly, in jumping in the first grade there was a marked difference, but after the first year there was no difference. In throwing the difference gets larger yearly, in the yearly growth growth rate the girls growth of throwing compared to that of the boys is $\frac{1}{2}$ or less every year, so it is natural that the difference grows larger.

2) The Yearly Change in Posture :

In Brown-Fisher's convinient posture, side pictures were taken and Thomas's classification was used. When we compared this for the last 3 years, both boys and girls in the lst and 2nd grades had about $60 \%$ of $\mathrm{C}$ type, no A type, and boys about $10 \%$ and girls about $17 \%$ of $\mathrm{D}$ type. In the 3 rd grade, boys and girls had $4.0 \%$ and $2.9 \%$ A type, especially about half the boys were B type and both sexes seemed to improve their posture. It has been reported by Ando and Hirai, etc. already that the school childrens' posture improves yearly. I have experienced quite a few cases of kyphosis which has been problem many times at the school health examinations. Next when we look at the relation between posture, physique and athletic ability, Nakayama, etc. say that in the lower grades the posture and athletical ability have mutual relations, but from my observation I couldn't find any relationships.

3) The Physique and Physical Strength: 
In the new semester of this school year we examined 111 boys and 109 girls. They were judged by Hirata's method concerning the physique and physical strength and if the total was above 0 it was called A class, $0-2$ was called B class and under -2 was called $\mathrm{C}$ class, and for 3 years we examined the body growth of the three classes comparatively.

When the 3 classes were compared yearly with sexual difference, in the first year there could already be seen any difference in the physique and physical strength in both sexes. In boys the difference is clear in the third year but in girls the difference in the third year between $\mathrm{B}$ and $\mathrm{C}$ class is not remarkable. Vervaeck Index in boys were, A class 68-69, B class 63, C class 65-66 and in girls, A class 67-68, B class 66-67, $\mathrm{C}$ class 64 and a marked difference can be seen according to the strength of the physique and physical strength.

Thinking these over, grammer school students especially in the lower grades, the physique and physical strength is to some extent determined by inherent factors but like the third grade girls the difference between $B$ and $C$ class could not be observed, so I think suitable physical education can make the physique and physical strength better and I would like to continue this investigation further in the future.

\section{LONGITUDINAL GROWTH STUDY ON SCHOOL GHILDREN. (Report 4)}

\section{H. FUNAKAWA. \\ Institute of Public Health}

For the last 10 years we have been investigating the process of body growth of children of a certain grammer school in Tokyo. All the examining was done by the same person. This time we have tried to analyse 624 students (male 300, female 324) which we have studied for 6 years consecutively.

With the thought of analysing the relation between the body type when entering school and the later developement, we have divided them into 5 groups; above normal (above $M+\frac{3}{2} \sigma$ ), good $\left(M+\frac{2}{3} \sigma \sim M+\frac{1}{2} \sigma\right)$, medium $\left(M+\frac{1}{2} \sim M-\frac{1}{2} \sigma\right)$, poor $\left(\mathrm{M} \sim \mathrm{M}-\frac{1}{2} \sim \mathrm{M}-\frac{3}{2} \sigma\right)$, and bad (below $\left.\mathrm{M}-\frac{3}{2} \sigma\right)$. With the combination of height and weight of these groups a total of 25 groups has been obtained and we examined the yearly development of each group for 6 years.

From among these this time we will report on the morphological items and the growth development of the ones with the height and weight included in the medium class.

When we make the growth rate 100 at the time of entering school, the growth rate of the next 7 items; height, weight, chest girth, sitting height, head girth, arm girth and the width of the hip would be like shown on the graph. The orders were with boys ; l. weight, 2 . height, 3 . sitting height, 4 . chest and arm girth and width of hip, 5. head girth, while in girls it was, 1 . weight, 2 . height, 3 . width of hip and sitting height, 4. chest girth, 5. arm girth, 6. head girth.. It is interesting that the order of hip width and arm girth differs between sexes.

Next we will see the time of the most sexual difference. In height and chest girth 4-5 th grade and in sitting height 3-4 th grade. Therefore it is interesting that there 
is a difference in sitting height before the growth of height, weight and chest girth in girls before the prepuberty period. Also in hip width the girls are always larger than the boys but in arm girth it is the opposite and the boys are always larger than the girls. These are not only because of the difference in the fundamental growth tendency but we must always have in mind the difference of the daily life of the individual in and out of school. The head girth relation between sexes is just about parallel with the boys being a little larger.

Concerning the other groups besides medium we will report later.

\title{
44. A STUDY ON THE CONSTITUTION OF SCHOOL GHILDRENS BY VAERVEGK INDEX.
}

\author{
G. OGIHARA, S. DEGUCHI.
}

Institute of Athletic Physiology, Hokko, Osaka University,

To investigate the yearly body growth of school children, especially of the Japanese who have tasted the big social ordeal of defeat, is very interesting physiologically and biologically. We have since the Medical Congress of spring, investigated the physical structure of school childrens and used the Vaerveck index which is considered to have the best mutual relation between nutrition and body physique.

1) Investigation by the average index according to the age :

We have compared the average of the index table given in Suzuki's "Physical strength measuring method" with the 1954 and 1955 terms of a grammer school of Toyonaka-city. In boys with the exception of the 4 th grade, 1955 term compared with the 1954 term, the index figure increased and the physique became better. The 4th grade of 1955 (3rd grade in 1954) showed a low figure and this may be coincidental but they were childrens born in 1945 the year the war ended.

In girls, 1955 was better than 1954 in all cases. But the higher grades compared to the lower grades, were somehow not perfected.

2) With the establishment of body condition appraisal grades, the investigation index variates with the age so in order to appraise groups of various ages, it was divided into 5 stages based on the variation of the index figure and each given a grade, and we studied from this average. We also got the same results from the average index figure of before.

Conclusion :

1) The physique was better as a whole in 1955 than 1954 .

2) The physique of the 4th grade was bad.

3) From the appraisal method given above it was possible to investigate.

We would like to continue yearly investigations and make a physical condition standard according to the district.

\section{ON THE CALCULATION OF SURFAGE AREA OF THE CHILDRENS BODY.}

\author{
M. MUROHASHI, J. HIDAKA. \\ Keihin Womens Junior College
}

The calculation of the body surface area is very complicated and difficult. So by 
measuring the height and weight which is rather easy, and using these as a factor and multiplying a certain figure to this the approximate body surface area is obtained. This kind of calculation has been designed by many persons and because these methods are easy they are used to obtain the body surface area mostly. But these calculation forms are based on the physique of standard sized persons and it is doubtful if it can be used or not on persons with various physiques. $U p$ to now in measuring the body surface of childrens the Otani's form has been used. But this is based on the standard of weak persons so it is doubtful if a approximate figure can be calculated or not. We have examined the 2 nd grade childrens of the attached grammer school and compared the methods up to now with the covering method using Manila paper and Du Bois' Liner Formula. The results were, the adults' form was over valued and the childrens' form was under valued, and showed an approximate figure with the Otani's method but was not practical. Results are shown on the graph.

\title{
46. STUDIES ON THE PHYSIQUE OF FARM CHILDRENS
}

\author{
ISAO NARITA. \\ The Office of the Board of Education Kanagawa Prefecture \\ School Health and Physical Education Section \\ KAZUYORI WATANABE. \\ Yokohama City University, Department of Applied Physiology
}

At a school in a village in Kanagawa Prefecture we intensified calcium and vitamin A which is commonly insufficient in our country's food life. Results are as follows.

Method of Investigation :

Concerning nourishment we examined the quantity of food taken during 3 days (May 29, 30, 31, 1955) at each home and school and obtained the average food intake per day of 57 th grade childrens, a total of 171 childrens in 3 days.

-29 th was a Sunday so 3 meals were taken at home and the rest of the days' breakfast and dinner at home and lunch at school.

In investigating we obtained reports of the food at home and at school.

To increase the calcuim and Vitamin $\mathrm{A}$ we added $0.4 \%$ of pearl calc. to the flour and fed this for 82 days. (Jan-May, 1955) This intensified bread (flour $100 \mathrm{gr}$.) had $400 \mathrm{mg}$ of pearl calc, which is equivalent to $93.24 \mathrm{mg}$ of pure calcium. We also mixed 0.05 gr. of concentrated cod liver oil (2500 I.U. vitamin A, 250 I.U. vitamin D) into the supplementary food for 103 days. (Nov.-May, 1955)

The growth investigations were done twice, Jan. 17 and May 24, 1955 of 27 boys and 25 girls of the 5 th grade. Weight, height, sitting height, width of the shoulder, width of the hip, thickness of the chest, girth of the chest and the girth of the right arm were inspected.

All the 271 students were inspected for follicular ichthyosis, pelaris and trichophytia once a month for 5 months. Also the 5 th grade students were examined for follicular ichthyosis. 
Results;

Farm students' animal protein, calcium, $B_{1}, B_{2}$, and $C$, especially had a marked shortage.

In measuring the growth there was nothing special.

With the increase of calcium and vitamin A in school lunches, follicular ichthyosis and pelaris decreased.

With the combination of body resistant and use of medicine the trichophytia decreased.

\title{
47. TOPOGRAPHICAL DIFFERENGES OF THE GROWTH OF BREAST OF SCHOOL BOYS AND GIRLS AMONG THE AGRIGULTURAL DISTRICTS
}

\author{
Y. OGATA, H. OGATA, T. MINAMI \\ Department of Morphology, Research Institute for Diathetic Medicine, Kumamolo University
}

Concerning the relation between districts, geographical positions and the growth of the human body, it is thought that there is a tendency of lonely places like mountain farm villages and mountain villages having a low height growth and large chest girth growth.

We have investigated the growth of height and chest girth of the farm and mountain villages' school childrens around the Midorikawa area in Kumamoto Prefecture thoroughly in order to find the district and geographical differences between neighboring areas. The results are as follows:

1) At the present (1953) the childrens' physique in the mountain and farm villages are not the short and fat type.

2) The chest girth growth of farm villages growing rice and wheat are bad, especially before the puberty stage. The arm girth is also small.

3) The daily life of mountain village childrens are suitable for the chest girth growth.

\section{STUDIES ON PHYSICAL STRENGTH OFTHE HIGH-SGHOOL BOYS IN KUMAMOTO GITY}

\author{
Y.SAWADA, R.SAKATA, M. TOYOTA, S. OKA. \\ Department of Morphology Research of Diathetic Medicine, Kumamoto Universtiv
}

An investigation was done by the same peron for 3 years to see what effect various sports have on the male high-school students morphology and function.

Persons examined were students who entered the Kumamoto Kenristu Kogyo High School in the 1951 term. The examined items were ; height, weight, chest girth, arm girth(left and right), chest left and right diameter, chest front and back diameter, Yamada's body type index, body flexibility, lung capacity, length of thorax, back muscle power, grasping power (left and right), 100 meters running ability, standing broad jumping ability, throwing ability and climbing ability. In measuring, Martin's human body measuring method was used mostly, and besides Martin's human body 
measuring device, Yamagoshi KYS hand dynamometer, lung capacity meter and back muscle strength meters were used. And the body type index and athletic ability measuring methods were as follows;

Body Type Index $=\frac{\text { Chest left and right diameter } \times \text { chest front and back diameter }}{\text { thorax length } \times 1 / 3 \text { height }} \times 10^{2}$

Standing jumping ability $=$ standing broad jump distance $\times$ weight $(\mathrm{kg})$

Throwing ability $=$ total of both arm throwing distance $(m) \times$ weight of ball(ounce)

$$
100 \mathrm{~m} \text { running ability }=\frac{100}{\text { running time }} \times \text { weight }(\mathrm{kg})
$$

Chinning ability $=$ time (number of) +2 (body weight $\mathrm{kg}$ ) -24

When we fixed the maximum and minimum figures of 13 items; height, weight, chest girth, arm girth, body type index, lung capacity, back muscle ability, left grasping power, right grasping power, jumping ability, throwing ability, running ability and climbing ability, athletes held 11 maximum figures and nonathletes held only 2. The athletes held only one minimum figure while the nonathletes held 12.

Next from the average figures and standard variations of 8 items; height, weight, chest girth, lung capacity, back muscle power, running ability, throwing ability and jumping ability we established 5 grades, large, rather large, normal, rather small and small, and made a physical strength measurement table and studied these.

Compared with the first year (1953) and this year (1955) in the physical strength measurement table. there is a marked increase of weight and back muscle power.

This year's average figure of ping-pong and tennis athletes were about the same or poorer than the non-athletes, but the average figures of rugby, soccer, track and field, judo, boxing, swimming, basketball, volleyball and baseball athletes were larger than that of non-athletes. Especially with baseball, rugby and volleyball athletes whom had anticipated in inter-school games and had good results, the physical strength measurement tables showed a much larger result than the other tables. In other words the physique and physical strength were both excellent. The body strength measurement table of ping-pong and tennis athletes were poorer than the other athletes, but with two years practice they became better than the other athletes. Also the increase in two years of the 8 basic items of the physical strength measurement table of athletes compared to non-athletes only the two, back muscle strength and jumping ability were poorer and the other six had increased remarkably yearly.

Our body structure has much to do with living conditions and influences besides hereditary and surrounding influences so it is very difficult to name the main factors. But from the above facts we think that it can be said that athletics has some influence on the body structure.

\section{PHYSICAL STRENGTH OF LONG DISTANCE RUNNERS OF HIGH SCHOOLS.}

\section{S. KOBAYASHI \\ Osaka City University}

Post war, sports was the most popular way of recovering Japan mentally and physically. One month after the war the movement to recover the Japan Amateur 
Athletic Association was seen.

The next autumn inspite of difficult surrounding conditions the first National Athletic Meet was held in Kyoto and it's vicinity. All Japan Inter-high Station Transmitting Race (Ekiden) was planned as a part of sports rehabilitation. Since 1950 in the latter part of December it has been done consecutavely by the sponsorship of the N.R.R. The race was done in Osaka with the round trip disiance of 42,195m. The road had some hills but the large portion was paved and without hills. There was quite an amount of cars on the road outside the Osaka city limits. The ages were $15-19$ and 16 and 17 were the most with 18 next and 15 and 19 were only about $10 \%$. The total was about 350 persons with the preliminary of about 7000 persons. The athletes came from all parts of Japan. The results were very good.

We examined the many physical factors and made many investigations.

\title{
50. INVESTIGATION RESULTS ON THE ANNUAL MARA- THON RACE OF A GERTAIN HIGH SGHOOL.
}

\author{
H.MATSUMOTO, A.KUYAMA, M.NAGASAKI, K.TAKAHASHI, \\ K.MAEDA, G.MURATA, N.SAKAMOTO, T.NAGATA. \\ Kanebo Hyogo Hostpital
}

We made many examinations before and after an annual marathon race of a certain Hyogo Kenritsu High School. From these results we would like to find the medical profits of this sport and use the data for the investigation of fatigue.

Because this marathon was for the general students we have limitted the factors which would make a difference in the results as much as possible. (Omit athletes, to avoid lazy students and mark experimenting students, have teachers on the road, omit students with parasites.)

Marathon Condition.

Date : February 11, 1955 9.00-9.50 AM

Weather: Clear. Temperature 9 degree C. Humidity $74 \%$

Course : $7000 \mathrm{~m}$. Valley and gravel read.

Time : 28 minutes 6 seconds--50 minutes.

Students : First grade high scnool (15-16 years) 24 students.

To measure fatigue the combination method is said to be the best. So with this number of students (24) we made as many examinations as possible. Examined items and results.

1) Examination of subjective fatigue symptoms.

The Industrial Fatigue Committee's method was used. The next items-physical, sensible, sentimental, ideal and nerve-had less fatigue feeling right after the race than before, but showed a very acute fatigue from the stand point of will. The sudden burden first severely hit the will and on the other hand as is reported later objectively there is a severe fatigue, but subjectively fatigue is rather lighter. This is a point a manager must realize.

2) Objective examination.

(1) Circulatory and respirative system.

Marked increase in the maximal and minimal blood pressure, decrease of the 
blood and pulse pressure index (Strausburger), difference and a markable increase in the pulse beat between standing and sitting pulse could be seen. Increase of the lung capacity and decrease of the measurement around the leg could be seen.

(2) Blood elements.

Decrease of hemoglobin, hematocrit, and serum $\mathrm{Cl}^{\prime}$ density, increase of serum protein (albumin and globulin) increase of leucocytes with increase of neutrophilic leucocytes and lymphocytes and decrease of blood alkali reserve could be seen.

(3) Metabolim system.

Decline of specific gravity, $\mathrm{Ph}$, and $\mathrm{Cl}^{\prime}$ of urine, protein reaction positive in most cases and marked increase in Donaggio and Takeya reactions, and Hamazaki's material quantity could be seen. The number of sedimentation test tubes in Takada serum reaction increased a little.

(4) Endocrine system.

Less than $50 \%$ decline of eosinophilic leucocytes could be seen in most cases.

(5) Reaction function.

Knee reaction increased very much.

Summarizing the above investigated results we think that this marathon had produced secondary fatigue.

3) The degree of fatigue of the indivisual and Pignet-Virvaeck Index.

We gave points for the degree of difference of the indivisual concerning circulatory respirative system, blood elements and matabolism system, and made a scattered diagram between the Pignet-Vervaeck Index and the points. These two showed 10\% danger rate and had counter correlation.

Summary.

1) In this marathon subjective fatigue symptoms were much stronger mentally than physically.

2) Objectively we think as a whole secondary fatigue phenomenom appeared. Therefore we think that this is in the healthy fatigue limit.

3) We must take great care especially in omitting people with circulatory and urinary system insufficiency.

4) From the change in the matabolic system we must take great care in the recovery of fatigue before and after the race.

5) From the change in the endocrine system in marathon the effect of training can be seen.

6) From the influence on the reflex function we must take care in the course for stumbling and other accidents.

7) The indivisual fatigue degree and Pignet-Virvaeck Index showed $10 \%$ danger rate and had counter correlation. We can learn a lot from this.

\section{STUDIES ON HIGH SGHOOL ATHLETES' PHYSIQUE.}

\section{ISAO TAKAGI}

Third Internal Medicine Department, Osaka Uuiversity

I have performed medical examinations since 1954 concerning the respiratory circulatory systems of high school athletes with the cooperation of the orthopedic 
department of the prefectural education committee.

The results were as follows;

In 1954 I performed medical examinations of 258 persons (male 173, female 85) in 10 sports and among them 14 required the respiratory system precise examination and among these 1 required attention, 1 required observation and 1 required treatment. In the circulatory system 1 required attention. Among the 385 persons examined in 1955, 40 required precise examination in which the repiratory system had 5 who required attention, 3 observation and in the circullation system 4 required attention. The above persons had no symptoms at the time of the April school health examination.

The above is only the results of the medical examination and the sickness rate of athletes and must still be investigated in the future.

\section{INVESTIGATIONS ON THE HEALTH AND PHYSIQUE OF COAL-MINERS.}

\section{SHIOTANI}

Tokyo Institute of Technology

1. The Object of this Investigation: As one of the investigations of the counter measure of deformities and habits according to the occupations, we have investigated the miners of a certain coal mine.

2. The Contents of the Investigation: We tried to grasp the actual conditions of the physique and health from as many ways as possible. Also we investigated the cause and in order to find counter measures we examined the health condition, physical strength condition, pictures of nude front, side and back, body frontal, dorsal and lateral flexions, dorsal ventral, lateral X-rays of the thoracis and lumbar vertebra, working conditions, working contents, working abilities, daily schedules, sports, hobbies, pleasure, education, economic conditions, etc.

3. The Standards of the Persons Examined: Persons who had much influence of mining work with over 15 years experience and ages about 40 years old.

4. Time of Investigation : August 4, 1955 from 9AM to 3PM. X-rays were taken in the next few days.

5. Type of Work of the Persons Examined: Persons examined were 3 kinds, gathering, hauling and digging coal inside the mines.

6. Observation of the Results : The results of the investigation are as follows;

(1) The age and experience years were all near our standard except one had only 8 years experience. (2) From the results of the health examinations, the present conditions and the tendency of getting sick were, 24 persons (83\%) had complains of some sort of disorder, with quite a few having complains of disorders while working. Among these lumbago was the most with $59 \%$ and together with knee and shoulder pains it was $80 \%$ and there were many so called neuralgies. Next were stiff shoulders and stomach sickness. Besides these persons with past records $38 \%$, wounds $72 \%$, blood pressure average $118.2-65.0 \mathrm{hgmm}$ and no abnormality could be seen. (3) The results of the physical examinations are, a) Height and weight average were a little 
lower than the averaged persons'. b) The horizontal level of the shoulder seen by the frontal-dorsal pictures and inspection were a little different according to the work but $62 \%$ were uneven which seems a little to many. c) From the dorsal pictures and inspection $69 \%$ had spinal abnormalty which seems numerous compared with the other occupations. d) The X-ray findings of the thoracic and lumbar vertebra, bone spur formation, wedged shape fracture, fish shape vertebra, Schmorl's body, scoliosis, irregulation of the processes spinosa, etc., disorders could be seen in $97 \%$ which is very numerous. e) From the frontal, dorsal and lateral flexion pictures of the lumbal region the frontal flexion degree was a little deeper and as a whole the movability range seems a little smaller than the same aged other occupation persons.

7. The Studies of the Causes and it's Counter Measures : From the above investigations the health and physique of coal miners do not seem to be very good. There are about 40 coal-seams in this mine and the tunnels are very narrow and low, mechanism is difficult and in some places digging is done crawling, so these bad conditions could be a large factor. As can be seen from the results of the investigation, the most fatigued place of the body is the lumbal region and lumbagos, lumbar vertebra deformities and shallow flexion could be seen and this could be caused by the lumbal flexion working posture in low tunnels. Also it seems the cause of spinal deformities could be because the body is always used on one side only. Therefore as a counter measure the inlargement of the tunnels, mechanism, rationalzation and compensation reformation of the working methods can be considered but this will be abbreviated.

\title{
53. STUDIES ON THE INFLUENCE OF CONFINEMENT ON THE BODY FUNCTION (Report II)
}

\author{
K. YAMAGUCHI, O.HIMI, C. DAIGO. \\ Hachioji Medical Prison \\ S. SUZUKI \\ National Institute of Nutrition
}

Introduction: In order to see what effect confinement life had to the physical body, we have studied 5 persons after having confinement life for 20 days and investigated the changes in the physique and nutrition conditions and found the decrease of basic metabolism, weight and blood circulation function. In the two previous experiments the confined persons were given food prescribed by the Ministry of Judical Affairs, $2867 \mathrm{cal}$. when working and $2087 \mathrm{cal}$. when not working, so the physique and nutrition decrease had been caused not only by the confinement life but food nutrition had much to do, so this time the food condition was changed to 2867 cal. when working and $2490 \mathrm{cal}$. when not working and the experiments were done the same as before.

Method of Experiment: Three persons were the same as before and only one differed. The physical condition and life condition were the same as the first report. The period of experiment was 47 days, May 14-June 29, 1955, 9 days preliminary period, 8 days working period, next 20 days confinement period and next 10 days working period again. The room temperature was $13-15^{\circ} \mathrm{C}$., higher than the last 
time. The measured items and methods were just about the same as before.

1) Basic Metabolism : Douglas' bag method.

2) Body Density: Measuring the over flowed water going in the bath tub up to the head.

3) Weight : Before breakfast right after taking in gas.

4) Blood Pressure : By Rivo-Rocci's sphygmonameter.

5) Stress Test : Like before counting the pulse at rest time and next counting the pulse after doing push-ups for one minute and 20 seconds and investigated the pulse increase.

6) Blodd specific gravity by sulfate of copper method and serum albumin by Hitachi's serum albumin meter.

7) Grasping power by hand dyamometer, back muscle power by K.Y. back muscle meter. The maximum figure of 3 measurements were taken.

From the above experimental conditions and methods we have obtained the following results :

1) Very little decrease in basic metabolism.

2) Weight decreased about $1.2 \%$.

3) Slight increase in body density.

4) From 2) and 3) we found that the weight decrease was caused by the fat tissue.

5) We reconfirmed that there was a close proportional relation between the basic metabolism and body density.

6) Decrease in muscle strength.

7) From the stress test blood circulation function decrease was seen.

From the above results it can be seen that with 20 days confinement, even if adequit food is given if there is no physical movement the nutrition condition does not decrease but functionally there is quite a bit of weakining. On the other hand internally from about 15 days confinement there is a slight decrease in the activity of the active organs.

\title{
54. ON THE ALLOWABLE LIMITS OF THE AMOUNT OF MUSGULAR EXERGISE
}

\author{
YOSHIAKI SUZUKI \\ Department of Hygiene, Showa Medical School
}

When the practice of sports goes past a certain amount, we can not anticipate on the effect of the practice but I think from the over work and fatigue our health and athletic ability will decrease. At the present to find out what effect the quantity of practice have on the athletes, we have had a few adults (men) use the bicyle ergometer and measured the physical functions according to the various stresses and the results are as follows;

1) If the stress of the labour is the relative metabolic rate (R.M.R.) and the labour stress is under 4.5, the oxygen intake and pulse rate are about normal for about 2 hours, but above this the oxygen intake and pulse rate has a tendency of increasing.

But if he labour stress is about 7-9. R.M.R. the pulse increaes and becomes about 
$180 /$ min but the oxygen intake doesn't increase.

When the labour stress is 4.5-7.0 R.M.R., the active variation differs according to the labour stress and the oxygen intake increases, but above this with a very strong stress the body must take action according to the maximum stress from the beginning and there is no surplus so such a developement occurs.

But if the strength of the stress is still increased, it becomes impossible to match this and it seems that usually the oxygen intake increases remarkably.

So the maximum strength of the stress for a normal male adult is 7-9 R.M.R. and if this sort of stress is continued till the pulse becomes over $180 / \mathrm{min}$. it can be continued for only about 40-50 minutes.

2) At the end of the stress when the pulse is $185 / \mathrm{min}$. and about $155 / \mathrm{min}$., if the relation of the strength of the stress and the period of the stress is drawn on a logarithmic graph, two straight lines like the graph can be obtained.

From the character of the pulse rate, the former is the limit of the stress of the labour agony which can be endured and the latter is the limit of the stress which has agony up to some extent.

The training of sports are usually done inside of the stress limit of the former, but some athletes do training with R.M.R. about 7.0 twice a day and 2 hours at a time. But these athletes can stand a stress of about $20 \%$ more than a normal person so the limit line can be drawn at a $20 \%$ increased location.

From these facts we think that these athletes practice up to were they can't endure the agony any more. Also the amount of practice of the numerous sports might be the same but some have very strenuous practice and the stress on the respiratory and circulation systems increases and the recovery is delayed remarkably so if a adequate rest is not taken there is a possibility of exhaust. If adequate rest can't be obtained the stress of the practice should be continued for about 2-3 hours inside the individual athlete's normal condition permitted limit.

\title{
55. STUDY ON THE TRAINING AMOUNT OF SPORTSMEN (Report II) BOAT RACING AND SOGGER ATHLETES IN TRAINING GAMP.
}

\author{
K. ASAKAWA, Y. KAMATA, Y.SUZUKI. \\ Department of Hygiene Showa Medical School
}

In order to investigate the most effective practicing quantity of athletes, we have investigated soccer and boat athletes of two universities which have first class athletes. We have measured the energy metabolism during training camp and also it's time study and the daily living schedule. The results are as follows;

1) The strength of the stress R.M.R. (Relative metabolic rate) of boat athletes were, four work 15 , paddle $20-25$, strong rowing about 30 . This very simple coarse was done over and over but the quantity was very large. On the other hand the soccer practice was very complicated. The main thing was running with ball manipulation 20-40, using the ball and light stress gymnastics about 10, with the quantity rather small. 
2) The next graph shows that the boat athletes daily training quantity with very little daily variation, and the pulse rate per minute near the end of the practice was on the estimated limit line obtained when above $180 / \mathrm{min}$. and was $20 \%$ above the industrial labourers'amount as Suzuki has reported. Even if 4300 cal. a day in food is taken, if adequate rest is not taken exhaust will result.

These boat athletes have not only cut down on their daily life outside of practice, but took 11 hours of sleep and daily rest every 5 days.

But with this control these athletes showed the effect of training and obtained the All Japan championship, so it seems that this amount of training must be the athletes' allowable limit of training.

3) When soccer athletes had heavy practice it was about the same as boat athletes but on rainy days only a short time of running and gymnastics were done, so if the average of 10 days training camp was taken it would be equivilant to 2 hours of normal condition permitted limit strength of practice done twice a day.

Also this quantity is equivilant to Shirai's allowable limit of training which can be done everyday without strain.

Also the soccer athletes' daily labour amount was only $72 \%$ (labour amount 1180 ) and compared to the boat athletes' $90 \%$ (2178) which seems to have a little to spare.

\title{
58. A STUDY BETWEEN THE THRESHOLD VOLTAGE PRODUCING ELECTRICAL PHOSPHENE WITH INJURIES OF SPORTS-MEN (Report II)
}

\author{
NOVIE TORIYAMA
}

Department of Orthopedic Surgery, Yokohama University, School of Medicine

Among the athletes I have taken the rugby players and investigated their threshold voltage producing electrical phosphene value's daily and hourly changes, and compared these with the relations between injuries.

Method of Measuring :

Persons examined were 14 Waseda rugby players at summer training camp, 7 leaders with camp experience and 7 without camp experience. The camp was held in August 1955 for 13 days and measuring was done three times everyday, 8 AM, $1230 \mathrm{PM}$ and 730 PM. Takahashi's apparatus (reported before) was used and the voltage was increased by hand at a constant speed as possible from $\mathrm{O}$ to the time of the electrical phosphene and this voltage was read and the average of a few times was taken.

Rugby camp training is rather rough and the amount of training was especially large with the objective athletes. The threshold volatage producing electrical phosphene value had three timely variations according to each athlete but usually the value which increased from normal had a tendency of increasing up to the middle rest and slightly decreasing in the end.

As reported when we look at the tendency of the timely changes in the threshold value of the persons injured, the difference between the evening before the injury and the morning of the injury was large. Also the difference in the threshold value 
is large before the injury and shows a large change after the injury too. Besides these it seems there is a relation between the timely variation of the threshold value and the camp exerience, amount of practice and fatigue, especially accumulated fatigue. In this occasion it seems a large change appears in the threshold value and when this is connected with the injurable condition, it seems when the fatigue and value change gets large there is a tendency of direct proportional connection with injury. Also with the relation of the place of injury, the degree of injury, the variation of the threshold value by injury can be seen.

\title{
59. SCOLIOSIS IN SPORTS.
}

\author{
S.KIMURA, K.TAKAGAMI, M.FUJITA, S.MAEHARA. \\ Ritsumei-kan University, Kyoto Prefectural Medical \\ University, Orthopedic Department
}

Recently in a very short period, we have seen four teen-age patients whom had scoliosis due to sports or which were increased by sports. These patients were soft-ball and ping-pong atheletes. Three of these patients where treated unoperatively and one was treated operatively. The results were rather good. In order to find the connection between the cause of scoliosis and sports, we examined 681 students attending middle school and high school, anticipating in many kinds of sports. The result was that scoliosis was more frequent and severe in soft-ball and ping-pong atheletes. We think that this is a result of the posture and the stress caused by these sports.

Up to now the cause of scoliosis are as follows,

1) Congenital Scoliosis

2) Rachitic Scoliosis

3) Habit Scoliosis or Stress Scoliosis

4) Static Scoliosis

5) Cicatricial Scoliosis

6) Neuropathic Scoliosis

7) Pain Scoliosis

The ones which interest us the most now is the Habit or Stress Scoliosis and Rachitic Scoliosis, but in the patients (atheletes) we saw in the out patient clinic and investigations, no deformity caused by Rachitis could be found in the other bones of the body. Soft-ball and ping-pong which caused this scoliosis are sports played from the middle school and at this period (middle school) bone growth is still occurring. So at this time a violent posture forced by these sports could cause the occurrance of scoliosis. Because of this to avoid scoliosis a very close connection should be made with the doctors concerning sports and an annual health examination should be made in order to find this disease in a very early stage. Also everything should be done to help the mental and physical progress. Light scoliosis can be cured unoperatively with rather good results. Severe cases must be done operatively, but before and after unoperative methods must be combined and post operative treatment is very important. 


\title{
60. ELBOW JOINTS OF TENNIS PLAYERS
}

\author{
I.HIROSE, A.HAYASHIBARA, A.MATUSYAMA, \\ H. MATSUBARA.
}

Department of Orthopedic Surgery, Osaka University, Medical School

We have questioned 93 tennis players with "tennis elbow". Next we took X-rays and in order to see the actional functions of the elbow muscles, we used a 8 element pen writing osselograph and took the electromyogram of the biceps brachii, triceps brachii, brachio radialis, brachio radialis extensor and brachio radialis flexor muscles and made these do all sorts of movements.

Examined Results :

There was no traumatic history.

$\mathrm{X}$-ray findings were like the other athletes especially like the pitcher, early closure of the epiphyseal line, thickening of the balkin of the using arm, sclerosis, and the thickening of the bone density part.

Electromyogram results were, tennis players had a tendency of stronger extensor muscles than flexor muscles and used them more.

Concerning elbow pains 37 out of $93(39.8 \%)$ had it. No relation between the origination and the tennis experience could be seen. The frequency was, spontaneous pain in men $26.5 \%$, tenderness $45.1 \%$, in girls spontaneous pain $13.9 \%$, tenderness $34.5 \%$. Location of the pain $\mathrm{n}$ as, 34 out of $37(91.9 \%)$ external condylus, and only $3(8.1 \%)$ internal condylus. Concerning the origin, sudden over strain of the contraction of the brachio-radialis muscle and brachio-radialis extensor muscle etc., the abnormal irritation of the periost and the crack in the adhere point of the tendon could be the cause of the pain. Also the process is not fast like pitchers and can't say deffinately what the origin is, but 37 out of 93 had pain which is a rather high rate, so in the future this must be investigated clinically and roentogenographically.

\section{0'. STUDIES ON THE ATHLETES' ELBOW WITH OSTEO-GHONDRITIS DISSEGANS}

\author{
A.HAYASHIBARA, A.SUGIYAMA, Y.MORIZAKI. \\ Department of Orthopedic Surgery, Osaka University, Medical School
}

We have performed operations taking out the nekrosed parts of the cartrage and joint free bodies in some of the athletes with osteo-chondritis dissecans.

We have obtained the following results :

1) It is seen mostly in males about 20 years old.

2) In baseball it is mostly seen in pitchers.

3) There is no special trauma history of the elbow.

4) We have found this in some persons with only shoulder pain complains.

5) We have found free bodies even in cases with the X-ray findings negative.

6) It seem there were no impediments post operatively in playing sports again. 
7) We have seen cases improved with only physical treatment.

8) There seemed to be hardly any relation between the period of the onset of the pain and the operation.

9) There were cases where it occurred familarily.

10) There were cases where is occurred on both sides.

\title{
61. THE EFFEGT OF WEIGHT ON THE PHYSIQUE
}

\author{
Y. OKA, K. NODA, E. BANDO, T. NAKAYAMA \\ H. MIYAMOTO, T. SASADA. \\ Department of Physiology, Tokushima University
}

In order to see what effect weight lifting had on the physique and physical strenght of a growing high school student, we examined 7 persons' physique (height, chest girth, weight, sitting height, front and back diameter of the thorax, left and right diameter of the thorax, width of hip, width of shoulder, neck girth, waist, arm girth, thigh girth) and statistical physical strength (back muscle strength, back muscle durability, shoulder arm strength, grasping power, lung capacity, breath hold ing time, maximum out haling pressure, blood pressure) before training and about 4 month after training continuously and studied the results.

Results were compared to before the training. Height shoulder width ratio, height chest girth ratio, height thorax front and back diameter ratio had a tendency to increase, height waste ratio, height hip width ratio had no change, height neck girth ratio, height thigh girth ratio decreased a little. Height lung capacity ratio and maximum out haling pressure increased but the maximum and minimum blood pressures both decreased some. Also in measuring the muscle power, weight back muscle strength ratio, weight shoulder arm strength ratio increased remarkably, height arm girth ratio also had a tendency to increase a little but grasping power index (weight left and right grasping power average) had very little change.

When weight lifting is continued the body muscles all grow but not all the muscles develope the same. First the chest muscles, back muscles and arm muscles groups increase remarkably.

\section{STUDY ON MUSCLE HARDNING DURING JUDO TRAINING}

\author{
K. KOGA \\ Department of Orthopedic Surgery, Osaka University \\ K. NAITO, Y.HATA. \\ Department of Orthopedic Surgery, Osaka Welfare Pension Hospital
}

We have measured the hardness of the biceps brachii muscle and gastrocnemius muscle of 38 males practicing judo (age average a little over 18 years) during practice and at tournaments with a SA type duro-meter. The results are as follows:

1) The hardness of the gastrocnemius muscle during practice increased gradually without any connection of left or right or ranks, but in the biceps brachii muscle, 
especially in low ranking persons had a tendency of decreasing and was remarkable in the right arm.

2) The hardness of the biceps brachii muscle in high ranked persons usually had a tendency of gradually increasing. In persons with low ranks there was a strong tendency of decreasing.

3) The biceps brachii and gastrocnemius muscles' hardness decreased or increased after practice parallelly.

4) The biceps brachii muscle hardness in a tournament had a clear tendency of decreasing in the right an increasing in the left.

\title{
63. STROBOGRAPHY OF BROADJUMPING.
}

\author{
Y.OGAWA, T.SUZUKI, S.YUSA. \\ Department of Applied Physiology, Yokohama Municipal University
}

We have reported at the last Medical Congress about the simple consecutive photography device. This device is the revolving sector method and takes many pictures on the same film. This time we used university students and took pictures of the running broad jump action,

We examined 77 persons and the average jumping distance was $4.56 \pm 0.31 \mathrm{~m}, 50$ meters sprinting time $7.8 \pm 0.4$ seconds, 10 meters sprinting time $1.4 \pm 0.1$ seconds. sergent jump $38.6 \pm 52 \mathrm{~cm}$ and the 10 meter sprinting time was measured 10 meters before the goal, running 30 meters. Each item was measured 3 times and the maximum figures were recorded.

From these records there was not very much correlation between the jumping distance and sprinting time, but there was some correlation between seargant jumps and broad jump distance.

We have made two calculating tables in order to find the logical jumping distance from the individual's athletic ability. We have obtained the jumping speed and angle of the gravity center of the body from the seargant jump and 10 meters sprinting speed and from the jumping speed and angle the jumping distance is obtained.

The obtained jumping distance is the distance between the parabola line of the center of gravity when taking off and the height of the center of gravity before taking off is reached again, so it is shorter than the actually measured jumping distance.

So in order to jump the most effectively of course when taking off (jumping) the individual should use effectively his vertical jumping ability and warm up the running speed according to the logical angle but the distance between the terminal of the gravity center and the landing point of the foot varies according to the body position when landing and makes a lot of difference in the record. Therefore from 35 persons who had good results in the strobography taken, 8 persons bent backwards and then showed a frontal flexion posture with an average jumping distance of $4.91 \mathrm{~m}$, frontal flexion posture 19 persons with $4.48 \mathrm{~m}, 8$ without frontal flexion posture $4.43 \mathrm{~m}$ and as a whole, people with frontal flexion postures had better records.

When we take 3 persons, one with running broad jump records near the average 
record, one above the average and one below the average and match each other, it is clear that it is due to the difference in the physique. When we look at the consecutive pictures taken, we fined that persons with excellent records have effective landing postures.

Our device is not good for analysing the action precisely but the objective data of many people can be obtained so we think we can get a proper data of the action.

\title{
64. ON THE PHYSICAL ABILITY OF SPORTSMEN
}

\author{
K. ASAKAWA, V.SUZUKI, Y. KAMATA. \\ Department of Hygiene, Showa Medical School.
}

To find the pecuiliarity of the physical ability and physical characteristics according to the various sports, we have investigated the physical factors of field and track, boat, rugby and soccer athletes of 2 universities which have first class athletes and drew this on the physique graph suggested by Shirai before and studied the results which are summarized as follows;

1) A first class shot-put and hammer athletes' physique is not only very large quantitatively but is typically a muscular type physique and compared with a second class athlete the muscular strength and the width thickness growth, especially the arm girth when flexed is very developed.

A first class sprinters physique compared with a second class one is quantitavely small, but is a very well balanced physique. But these sprinters unfortunately, seem to have poor width thickness growth.

A first class middle distant runner is developed muscularily and has good width thickness growth, but a second class one's physique is not only small quantitatively but has a athletes physique and adaptable changes due to training couldn't be seen yet.

A first class long distant runner has a quantitatively rather small balanced physique similar to a gymnastic athletes' and didn't have a endurable type physique with a large lung capacity compared with the body construction as Shirai had reported before. A second class long distant runner had a quantitatively small athletic type physique and like the second class middle distant runner, showed no adaptability variation in the pecuiliarity.

A javilin athlete's physique ranks between the shot-put, hammer athlete and the middle distant runner. A first class jumper has very poor width thickness growth, but compared with the second class athletes they have a large lung capacity and muscular strength.

2) The physique of a rugby player differs according to the position and usually quantitatively the forwards are much larger than the backs. Also in the same forwards, the front athletes have marked width thickness developement and have a muscular type physique, where as the second and back row athletes have an athletic type physique with a large lung capacity. The backs are in between with a width thickness type physique. But a second class rugby player doesn't have a marked difference to the position, and they all have a physique like a back which shows 
relatively little adaptability changes in the physique.

3) First class soccer players had marked difference in physique according to the position like rugby players, but in second class players not only the adaptable changes could not be seen but also quantitatively they had relatively small physique.

A first class H.B. and F.B. was smaller compared to throwing athletes (field) but had quantitatively relatively large athletic type physique and second class F.B. had poor function compared with the body structure and had a physique like a intellectual labourer without balance.

There couldn't be seen much difference between the first and second class forwards, but the both had a light relatively meager physique.

4) A first class boat athlete had muscular type physique like the characteristics of the middle distant runners and throwing athletes combined and just like making the javelin athlete quantitatively larger.

5) The physique of an athlete not only had a characteristic physique which suites best in performing the sports but it was normal that if the type and amount of exercise is about the same the physique of the athletes had simular physique graphs of the parts which had close relations. Also these characteristic physiques had influence with the constitution, but from the difference between first and second class athletes adaptability by training seemed to have much to do.

\section{GARDIO-PULMONARY FUNCTION OF ATHLETES. (Report I) \\ K.YAMAKAWA, K.KITAMURA, N.OGAWA, S.IRIKI, R.IWATA, T.KATO, E.HARADA, S.OTA, T.SAITO, T.NAGASAKA, I.OTA. \\ Department II, Intermal Medicine, Faculty of Medicine, Juntendo University Y. KURADA \\ Japan Amature Athlete Association}

We have recently examined the cardio-pulmonary function of swimming athletes who participated in the Japan American swimming meet. We examined the vital capacity, the maximum ventilation volume per minute, the respiratory volume per minute, lung volume by Knipping's spirometer, chest X-ray (dorsal-ventral, No. I\&II oblique), ECG, and heart tone pulse curve, etc. and compared these with the findings of 18 healthy students of about the same age.

Concerning the lung function, the vital capacity and maximum ventilation volume were both increased compared with the contrast group but when we examine the rate of the Baldwin's estimated figure and unit body surface area of the latter there couldn't be seen any marked differences.

The vital capacity compared with the contrast group, both the inhale and outhale reserve increased and especially the increase of the inhale reserve was remarkable. The recidal air decreased but in the average residal air, there could not be seen a marked difference. The relative figure when compared with the contrast group, the inhale reserve and vital capacity showed a high figure and the residal air rate and residal air both showed a low figure. 
There was hardly any difference in the respiratory volume per minute, ventilation reserve rate and oxygen volume compared with the contrast group.

From the above we found the decrease of residual air rate in swimmers, and we think that the inhale reserve has much influence due to training.

Concerning the heart function we have only reported on the ECG this time. We found complete auriculo-ventricular block in one case. In all cases with the left precordial lead ST increased remarkably and found high peak T waves. We don't know if this is special in athletes but from the ventricular gradient gerneral index, in other words it can be explained by the increase of $\mathrm{G}$.

\title{
66. STATISTIC STUDY ON THE PHYSIQUE OF THE ATHLETES OF THE ALL JAPAN AMATURE ATH- LETIC MEET OF THE PAST THREE YEARS.
}

\author{
T. AZUMA, S. MIZUMACHI, Y. KURODA, M. OGASAWARA, \\ N. TORIYAMA, K. SATO.
}

Japan Amature Athlete Association

Of 53760 athletes of the 7, 8, 9th All Japan Amature Athletic Meet, health examination slips were handed in and a statistical observation of 18896 persons were made.

From the health examination, there was $30 \%$ improvement in the 7 th and 8 th meet and $45 \%$ improvement in the 9 th meet.

From the physique there couldn't be seen hardly any difference in the height, weight, girth of the chest and vital capacity of each meet. In most cases the height was $160-170 \mathrm{~cm}$ in males and $150-160 \mathrm{~cm}$ in females, weight was $50-60 \mathrm{~kg}$ in males and $45-55 \mathrm{~kg}$ in females, girth of the chest was $83-92 \mathrm{~cm}$ in males and $78-85 \mathrm{~cm}$ in females, the vital capacity was $3500-4500 \mathrm{cc}$ in males and $2500-3500 \mathrm{cc}$ in females.

But persons with X-ray findings in the chest increased with the expectation rate, and that of the 9 th meet was 6 times $(0.03 \%)$ of that of the 7 th and 8 th meet, so we think we must make efforts from the standpoint of the physical management of these athletes.

\section{THE BLOOD CONDITION AFTER SPRINTING}

\section{T. YOSHIOKA}

\author{
Department of Physical Education, Koyoto Gakugei University
}

To examine the physiological changes in the blood condition after sprinting, I had 3 university athletes with long training experience and non athletes and had them sprint for $300-400$ meters and examined the gas metabolism and blood conditions for 60 minutes.

1) Gas Metabolism

After sprinting the oxygen dept volume of athletes were about 13-14 1, and this 
figure is thought to be similar to the maximum oxygen dept volume, but in nonathletes it was 3-6 1 which is less than $\frac{1}{2}$ of that of athletes. It is doubtful if this figure of non-athletes is similar to the maximum oxygen dept volume.

The discharge of excess $\mathrm{CO}_{2}$ was larger than non-athletes.

2) Blood Lactic Acid Volume

The change in blood lactic acid in non-athletes were right after sprinting, 2-3 times of that of rest time (about $40 \mathrm{mg} / \mathrm{dl}$ ) and increased gradually. The maximum was $60-80 \mathrm{mg} / \mathrm{dl}$ about 10 minutes later. (6 times of rest time.) In athletes it was already $60-80 \mathrm{mg} / \mathrm{dl}$ right after sprinting which is a rather high figure and this figure continued for about 10 minutes. After this the recovery was about the same in both and decreased gradually and about one hour later it was around twice $(24-36 \mathrm{mg} / \mathrm{dl})$ of that of rest time.

\title{
3) Blood $\mathrm{O}_{2}$ and $\mathrm{CO}_{2}$ Contents
}

The $\mathrm{O}_{2}$ and $\mathrm{CO}_{2}$ contents of the whole blood after sprinting decreased a little after running in both athletes and non-athletes but the volume was inside the normal range variation. But in athletes it decreased right after sprinting and a few minutes later the $\mathrm{CO}_{2}$ contents decreased further (about 20 vol. \%) and this condition continued for about 30 minutes but the $\mathrm{O}_{2}$ contents increased contrariwise and recovered to about the rest time figure (20 vol\%) in about 30 minutes.

\section{4) Blood ph}

The ph decreased in both athletes and non-athletes after running. The amount of decrease was about 0.2 in non-athletes and in athletes some decreased excessively to about 0.4 and under ph 7 condition continued for about 10 minutes. The oxygen dept volume of these persons were $13.8 \mathrm{l}$. Also they had severe agony after running.

\section{5) Blood Specific Gravity}

The specific gravity of the whole blood and serum right after sprinting was, 1.060-1.030 with an increase of about $0.004-0.007$, but decreased gradually and became normal in about 30 minutes later.

In synthesizing the above results, the athletes' $\mathrm{O}_{2}$ dept volume and blood condition changes were much larger than non-athletes, in other words it seems that with continuous training the variation range of the blood condition which can be endured, becomes larger especially the ph index 7.0 condition phenomenon continues for a few minutes.

\section{OBSERVATION OF THE BLOOD BUILD AFTER SPRINTING.}

\author{
T. IZEKI, T. KONDO, F. MiKI.
}

The First Internal Medical Clinic, Medical Faculty, Osaka City University

For the last few years we have been making many observations on what influence athletics has on the blood. Among these we will report on the changes in the blood picture of the trial running of the 1953 and 1954 inter high $10000 \mathrm{~m}$ and $2000 \mathrm{~m}$ races.

The number of erythrocytes decreased 15 minutes after running 10000 meters in 1953 and in 1954 it increased right after running. From these facts we think the 
erythrocyte number increases right after running but decreases in a short period so we observated timely on 8 cases after practice running 2000-3200 meters. Of 4 cases when the blood was taken from the ear the erythrocyte count variated very much, but 4 cases when the blood was taken from the cubital vein the variation had parellel relations. The red corpuscles' count were parellel to the Ht figure, increased remarkably right after running, reverted to the former figure in 30 minutes, decreased slightly in 2 hours and reverted to about the former figure in 4 hours. Hb volume variation was less than that of the red corpuscle and because it decreased slightly more than the former figure, 30 minutes after running, the color index decreased slightly right after and 30 minutes after running, but contrariwise 2 hours later it increased a little.

The white corpuscle increased remarkably right after running, and 30 minutes later it became the same or lower than the pre-running figure, increased from about 2-4 hours later and these 2 kinds of variations were observed. The white corpuscles increase right after running and this was caused bythe relative and absolute lymphocyte increase, 30 minutes later increase seen was due to the neutrophilic leucocytes as seen when practice running 2000 meters, but compared to this right after running 10000 meters the lymphocytes' increase was slight and the neutrophilic leucocyte increase was remarable.

Using the Hinkleman's reagant and counting the eosinophilic leucocytes directly, right after 2000 meters practice running $27-68 \%$ increase was seen in all cases and 43-60\% decrease was seen 4 hours later. Compared to this right after running 10000 meters, 2 cases increased and the other 6 cases decrease $20-50 \%$ and 4 hours later a remarkable decrease of $72-94 \%$ was observed. The decrease of the eosinophilic leucocytes four hours after running is thought to be caused by the stress influence on the activation of the adrenal cortex and the difference between the practice running and 10000 meters race is thought to be caused by the physical stress and emotional stress of the meet on the activation of the adrenl cortex. Also when the physical stress has no influence on the activation of the adrenal cortex and if decrease is still observed it is thought that the emotional stress had influence before the race. With 2 cases with increases right after the race and one case with the least decrease, these were all inside of 5th place, so it can be estimated from the standpoint of eosinophilic leucocyte variation, that they had emotional composure before anticipating in the race. For instance when we compare the decrease rate of the eosinophilic leucocytes with the stress of the athletic events, it is in the order of 10000 meters, 2000 meters, volley ball and handball back, and in these cases even in the games besides practice the eosinophilic leucocytes decreased right after the events inspite of the athletic stress. On the other hand in the Kansai inter college boxing league the coaches, managers, and extra athletes at the ring side were observed for there eosinophilic leucocyte variation due to the emotional stress and 4 out of 5 cases had 53-77\% decrease after the match.

Next in order to find the difference between the blood build after the events of the ear and cubital blood, both bloods were taken from 3 athletes after running 2000 meters. Red corpuscle, $\mathrm{Hb}$ volume, $\mathrm{Ht}$ figure, white corpuscle had parellel variations in 3 cases of the blood from the cubital vein. On the other hand in the ear blood, the red corpscle and $\mathrm{Hb}$ volume right after running increased much more than that 
of the venous blood and one showed an entirely different variation compared with the venous blood. The white corpuscle count differed in one case compared with the venous blood. It can be noticed that the difference in the variation of the ear and cubital vein blood, in the case of red and white corpuscles they don't appear at the same time. Concerning the ear and cubital blood difference we will examine this further.

On top of Mt. Norikura about the same tendency could be observed, but was much more remarkable compared with that of the sea level.

\section{TIME STUDY OF TENNIS MATCH}

TATUSZO ASANO.

Educational Departement, Okayama University

As basic materials to measure indirectly the energy consumption during one tennis game the time study of various movements during the match was observed and is reported as follows.

This investigation was done on a total of 96 male and female players who were selected by the random sampling method of two tennis matches in Okayama. The time study of the various movements during the match and the number of times the ball was hit was measured. Among these movements, court change walking was normal walking a, during the match walking was normal walking $b$, slow running was normal running a, fast running was normal running $b$, and each required time was measured in seconds.

When we look at the average of the number of games and game time of one match (3 game match) from the gathered moving time of each of these courses, in the singles the males played about 19 games 50 minutes, and the females 14 games 32 minutes, in the doubles the men played about 21 games 54 minutes and the females about 22 games 62 minutes. So the average time for a single game was in men 2 minutes 42 seconds and females 2 minutes 22 seconds, in doubles men 2 minutes 31 seconds, females 2 minutes 21 seconds and the required time for one game was about 3 minutes and 20-30 seconds for one point.

When we look at the comparison between the various movements against the game time, in all four events the time of walking movement $(a, b)$ used about $55 \%$ of the game time, but in statical movements like standing and posture (about 30$40 \%$ ) doubles were more than the singles and among these females used more than the males, in running $(10-15 \%)$ they had opposite relations. In other words the movement of singles were more active than doubles and men were more active than females. This shows the characteristic of the tennis match, that the defensive range of the athletes of doubles are smaller than the singles, and the physical difference of the sexes in the games can be seen by the time study.

In counting the number of times hitting the ball, the type of hitting was divided into 14 types and counted according to the type and the total was obtained.

From this the total time hitting the ball was in singles men 343 times, females 117 
times, in doubles both sexes 160-170 times. Also the number of times hitting the ball in one game was in singles men 19 times and females 13 times and in doubles both sexes about the same with 8 times. The times hit to obtain one point was in singles men 3 times, females 2.5 times and in doubles both sexes about once.

Next the percentage of the type of ball of one game compared with the total was, in the 4 events $25-30 \%$ serve and the ratio of the first serve and second one was about $3: 1$, in other words 1 out of 3 was not good.

In other types of balls in singles of both sexes, grand strokes such as drive, slice, lobbing, chop, etc. were about $70 \%$ and net play such as volley and smash were only about $5 \%(\hat{\delta})-1 \%(\%)$. In doubles it was the opposite with the former decreasing to $46 \%$ ( $\hat{\delta})-63 \%$ ( $q$ ) with the latter increasing to $26 \%$ ( $\hat{o})-9 \%$ ( + ). This fact shows the difference of the characteristic of the game between the doubles and singles from the standpoint of the number of times hitting the ball. Also from the fact that net play is remarkably less in females than men it can be estimated that the females do not go up to the net and play positively offensively.

\title{
70. THE STUDY OF STUDENTS' FREE TIME (Report II)
}

\author{
Y.TOBA, N.MURAKAWA, C.SUZUKI, \\ K.HIRATA, S.MANO, R.ISHIGAKI
}

Keihin Women's Junior College

In order to grasp the living condition of students we have reported in our first report the free time rate of university, high and middle school students in the Kanagawa Prefecture. This time we have examined the free time rate of grammer school and harvest time high and middle school students. Results are as follows;

1) When we average the daily schedule of grammer school students, sleeping time is 9 hours 26 minutes, restricted time is 6 hours 37 minutes, half restricted time is one hour 4 minutes, free time is 6 hours 53 minutes, with the free time rate being $98 \%$.

2) Middle school students' daily schedule is sleeping time is 7 hours 55 minutes, restricted time is 7 hours 5 minutes, half restricted time is 2 hours 49 minutes, free time is 6 hours 11 minutes, with the free time rate being $88 \%$ and it seems that helping house work doesn't break the balance of the structure of the schedule.

The daily schedule during the busy farming season vacation is restricted time 4 hours 54 minutes, half restricted time 48 minutes, sleeping time 7 hours 36 minutes, and free time is the opposite as anticipated and was 10 hours 42 minutes and the rate was $153 \%$.

3) In high school students the sleeping times was 7 hours 8 minutes, restricted time was 6 hours 49 minutes, half restricted time was 3 hours 44 minutes, free time was 6 hours 19 minutes, with the free time rate being $90 \%$ and little difference between sexes.

From the above facts during harvest time, we found that the free time of middle school and high school students were not to little. 


\title{
71. STUDIES ON PHYSIOLOGIGAL AGE. (I) STUDIES ON THE RELATION BETWEEN MENARCHE AND STATURE, AND AGE.
}

\author{
TOSHI INOUE
}

\author{
Department of Hygiene, Faculty of Medicine, Shinsha University
}

It is said that stature expresses the physiological age to some extent. So to obtain some basic material for deciding the physiological age I have investigated on the relation between menarche and stature and age.

Concerning menarche, age and stature there already is Matusbayashi's report on girl high school students of Hiroshima. (Racial Hygiene 2, 1, 1, 1933) According to him, the average age of menarche was 14 years and 0 month, and the stature at the time of menarche was average $148 \mathrm{~cm}$ without any connection with the age.

My experiment is in some way a supplementary examination of Matsubayashi's results, but his investigation was done in 1933 and is very old. Students are getting prematured and taller at the present time, so it is a problem if Matsubayashi's results matches the present situation or not, or if his results of Hiroshima city is the same in farm and mountain villages.

Investigated objects were about 4500 middle school girls of 13 schools in Nagano Prefecture, about 2000 from the cities, about 2000 from the farm villages and about 500 from mountain villages. In investigating we gave each school inquiry slips and had the time of menarche, stature of September of this year and the stature after entering school noted down. The stature ot the time of menarche was obtained by the customary monthly height growth standard.

From the investigation, average menarche age and average height at the time of menarche were, in the city 13 years 8 month $148 \mathrm{~cm}$, in farm village 13 years 8 month $148 \mathrm{~cm}$, in mountain village 13 years 10 month $147.3 \mathrm{~cm}$, and there were no difference in the menarche age between the city and farm village but the mountain village was delayed 2 month. The stature at the menarche was the highest in the cities, lowest in the mountain villages but the difference was not so large. Compared with the results of Hiroshima (1933) the menarche age was 4 month earlier in the cities and farm villages, and 2 month earlier in the mountain villages but had little difference in the height at the time of menarche. But when the height at the time of menarche is examined it differs to Matsubayashi's results. Matsubayashi says that the height is $148 \mathrm{~cm}$ at the time of menarche and has no relation to age but from my results, the younger the menarche age is the shorter the height at that time is and this relation is especially remarkable in persons with menarche before $13 \frac{1}{2}$ years.

Next the menstral rate of the same age and same height was obtained and a graph of the age and height was made. The material is little so to some extent it is an estimation but for instance in persons with a height of $138 \mathrm{~cm}$ between 14 years 10 month-15years 4 month, $60-80 \%$ have menstration, and with the same height there is no person with menstration before 12 years 8 month and this is opposite to Matsubayashi's theory. 
From the above results it is certain that menarche has a close relation with the height and menarche also has relation with the age. Height comes in handy to some extent as a standard of the physiological growth but physiological growth can't only be obtained by the height.

A sepaate height and age menstration rate graph is being planned but I am sure by inserting the individual's age and height we can obtain the physiological age of the puberty girl students to some extent.

\title{
72. ON THE FLUGTUATION OF GRIP AND BAGK MUSGLE STRENGTH IN FEMALE WORKERS OF A SPINNING MILL DURING SUMMER OPERATION
}

\author{
IKUO HASHIMOTO
}

\author{
Toyo Spinning Co. Ltd., Komatsushima Mill Hosp.
}

The labor contents of a spinning mill is a typical light labor and fatigue both in summer and winter is very little. But in the summer because of the unbalance of the natural condition and body function the fatigue is larger to some extent compared with winter.

From this point of view I have examined the back muscle strength and gripping power variation of female spinning mill workers in the spinning and weaving course. The results are as follows.

The investigations were done for 3 month, May, June, and July of this year at the Toyo Spinning Co. Komatsushima factory in Tokushima Prefecture.

1) When we average the age, employed period, menstrual period and it's length and working quantity it is like the table and the former group in the table means going to work at $5 \mathrm{AM}$ and the latter group goes to work at $1: 45 \mathrm{PM}$, with both having 45 minutes lunch rest and actual working hours 8 hours, The number examined were 100 persons for each course and duty and B is spinning coarse and $\mathrm{S}$ is weaving coarse.

2) The table shows the average of the height, weight, chest girth, using arm girth, weight ratio, chest girth ratio, Vervaech index and the average figure of each course and each duty is about similar.

3) The table shows the timely change of the temperature and humidity during work in each factory. The temperature had some variation according to the course and duty hour but was not so remarkable. The humidity had quite a lot of difference because of the difference in the surrounding condition of the spinning course and weaving course.

4) The graph shows the variation of the right hand gripping power and before working is 100 and the increase and decrease rates are shown by the percentage of the preworking figure. (left hand gripping power and back muscle power will be described in the same way.)

$\mathrm{B}$ and $\mathrm{S}$ course, former and latter duty all have increased gripping power during work, but this variation is very large between B and S course and B course is larger. Also in both processes the latter duty is smaller. 
5) The graph shows the left gripping power and it is about the same as the right. In the right and left gripping power the variation is little in the $\mathrm{S}$ process and in the duty condition the latter duty is smaller. The cause of the difference in the former can be thought to be the difference in the labor contents and humidity, but in the case of the latter the cause is not clear. It might be the mental difference caused by the temperature and humidity.

6) $B$ and $S$ process back muscle power is shown and in both cases it increases during the work inspite of the former and latter duty. This variation when compared with the process in both the former and latter duties, B process is larger than $\mathrm{S}$ process and this is the same as the left and right gripping power variation. But the relation with the working hours, in the former duty it gradually increases becoming constant near the end of the work, but in the latter duty it increases remarkably compared with the former duty at first and after this increase and decrease continues. I think this difference can be found by inspecting the surrounding condition in the factory.

\title{
73. ROENTGENOLOGIGAL STUDIES ON THE SKELETTAL SYSTEM OF TWINS.
}

\author{
F.KONDO, K.MIKANAGI, I.TANGE, \\ S. YOSHIKAWA, N. YAMAZAKI
}

Department of Orthopaedics, School of Medicine, Tokyo University

Introduction: Hereditary factors have much to do with the morphological developement of skelettal system but on the other hand the posterior acquired factors can't be neglected. We have for the last few years made investigations on the X-ray of the bones of twins. From this we would like to investigate how much influence these factors have on the morphological developement of the bone.

The experimental objects were a total of 354 pairs who voluntered to enter the Tokyo University attached middle school.

Normal Morphology: We examined the foot, vertebra and shoulder joints. We compared the X-ray of the foot by looking transparently through these and found marked difference in the unanimity rate of the structure of the both ovular twins and it was larger in the uniovular twins.

It was the same with the vertebra with a much larger unanimity rate in between the uniovular twins and biovular twins. In the shoulder joints each part had been compared according to the kind of ovular twins and the shape of each place had much difference and this could be a help in the ovular differential diagnose.

Abnormal Morphology: In the vertrebra and foot many various changes could be seen. In the vertebra, the bone fusion was not complete and transitional vertebra and vertebral arch could be seen. There couldn't be seen any marked difference in the unanimity rate of the ovular twins but the origination in other words craniale variation and caudale variation had difference in between the ovular twins. The lumbar vertebra marked abnormalty is not definite because of the few cases. Concerning the vertebra arch it is the same. Concerning the os tibiale externum of the 
foot the ununanimity in the uniovular twins were much (2 times) and this seems to be controled by the surrounding condition factors more than the hereditary factors. Concerning the 5 th finger of the foot the dangerous rate is $5 \%$ and this difference has much importance and it can be said that this can be influenced by the hereditary factors very much. Concerning the os subtibiale the causes are few so it couldn't be compared. Concerning the os trigonum this was found only in one side and hereditary factors seems to be small. We have examined the other abnormal bones of the foot but because of the few cases we will leave this problem for later reports.

The Time of Appearance of the Bone Kern: Concerning this the inherent factor has much to do but with the influence of the surrounding condition there many be a little variation but we will abreviate it this time because concerning the age a thorough result hasn't been obtained.

Results : From the above results hereditary factors has much influence on the normal morphological developement and the surrounding condition factors has much influence on the abnormal morphological developement. But concerning the transitional vertebra, we think the cranial variation or the caudale variation has much influence on the hereditary factors. 